\title{
A DFT Study of Structural and Bonding Properties of Complexes Obtained from First-Row Transition Metal Chelation by 3-Alkyl-4-phenylacetylamino-4,5-dihydro-1H-1,2,4-triazol-5-one and Its Derivatives
}

\author{
Hubert Jean Nono, ${ }^{1}$ Désiré Bikélé Mama, ${ }^{2}$ Julius Numbonui Ghogomu, ${ }^{1}$ and Elie Younang \\ ${ }^{1}$ Department of Chemistry, Faculty of Science, University of Dschang, P.O. Box 67, Dschang, Cameroon \\ ${ }^{2}$ Department of Chemistry, Faculty of Science, University of Douala, P.O. Box 24157, Douala, Cameroon \\ ${ }^{3}$ Department of Inorganic Chemistry, Faculty of Science, University of Yaoundé I, P.O. Box 812, Yaoundé, Cameroon
}

Correspondence should be addressed to Désiré Bikélé Mama; bikelemama@yahoo.fr

and Julius Numbonui Ghogomu; ghogsjuju@hotmail.com

Received 12 December 2016; Accepted 3 May 2017; Published 3 July 2017

Academic Editor: Konstantinos Tsipis

Copyright (C) 2017 Hubert Jean Nono et al. This is an open access article distributed under the Creative Commons Attribution License, which permits unrestricted use, distribution, and reproduction in any medium, provided the original work is properly cited.

\begin{abstract}
Density functional calculations were used to explore the complexation of 3-alkyl-4-phenylacetylamino-4,5-dihydro-1h-1,2,4triazol-5-one (ADPHT) derivatives by first-row transition metal cations. Neutral ADPHT ligand and mono deprotonated ligands have been used. Geometry optimizations have been performed in gas-phase and solution-phase (water, benzene, and N,Ndimethylformamide (DMF)) with B3LYP/Mixed I (LanL2DZ for metal atom and 6-31+G(d,p) for C, N, O, and H atoms) and with B3LYP/Mixed II (6-31G(d) for metal atom and 6-31+G(d,p) for C, N, O, and H atoms) especially in the gas-phase. Single points have also been carried out at $\operatorname{CCSD}(\mathrm{T})$ level. The B3LYP/Mixed I method was used to calculate thermodynamic energies (energies, enthalpies, and Gibb energies) of the formation of the complexes analyzed. The B3LYP/Mixed I complexation energies in the gas phase are therefore compared to those obtained using B3LYP/Mixed II and CCSD(T) calculations. Our results pointed out that the deprotonation of the ligand increases the binding affinity independently of the metal cation used. The topological parameters yielded from Quantum Theory of Atom in Molecules (QTAIM) indicate that metal-ligand bonds are partly covalent. The significant reduction of the proton affinity (PA) observed when passing from ligands to complexes in gas-phase confirms the notable enhancement of antioxidant activities of neutral ligands.
\end{abstract}

\section{Introduction}

In recent years, the repercussion of free radicals and reactive oxygen species (ROS) in neurodegenerative disorder is more sensitive [1-4]. The contribution of these ROS to the pathophysiology of myocardial reperfusion damage. These ROS can be oxygen-centered radicals [5] or oxygencentered nonradicals [6]. The removal of electrons from cellular membranes by these ROS and the reaction between these latter ones and proteins [7] provoke the alteration of the structures of these membranes and proteins. Such alterations justify the frailty of these cellular membranes that expose them to be attacked by invaders (viruses and bacteria).

Nevertheless, each cell is naturally equipped by defense systems against any destructive effect of ROS. This statute of protective mechanism against ROS in humans is attributed to antioxidant molecules $[8,9]$. In general, antioxidant molecules (tocopherol (vitamin E), ascorbic acid (vitamin C), carotenoids, flavonoids, and polyphenols) prevent the proliferation of free radical reactions in all cell membranes. This explains the emergence of studies on the investigation of antioxidant activities of biologically active compounds. This has led to increased pressure on the need for the newer 
molecules which may have potentials to curb the spread of this problem. Particularly, 1,2,4-triazole and its derivatives have been reported to possess antioxidant activities [10-13]. The 1,2,4-triazole derivatives have also been known to possess many biological activities (antifungal, analgesic, antiviral, anti-inflammatory, antitumor, anti-HIV properties, etc.) [14, 15]. It is worthwhile to mention that 1,2,4-triazoles have been prepared by different methods. The cyclodehydration of acylthiosemicarbazides with a variety of basic agents is the most common method used. The literature survey revealed that acylthiosemicarbazides are the key intermediates used in the synthesis of 1,2,4-triazol [16, 17].

Our previous research was focused on the theoretical analysis of antioxidant mechanisms of 1,2,4-triazole derivatives [18], more precisely of 3-alkyl-4-phenylacetylamino-4,5-dihydro-1H-1,2,4-triazol-5-one (ADPHT) derivatives. The calculated thermodynamic properties descriptors calculated in gas and solution-phases were Hydrogen Atom Transfer (HAT), Single Electron Transfer-Proton Transfer (SET-PT), and Sequential Proton-Loss Electron Transfer (SPLET) mechanism. Results indicated that, thermodynamically, HAT mechanism is the most predominant process in the gas-phase. But, in solvents (2-propanol, acetonitrile, DMF and water), the SPLET mechanism has shown to be more preferred. It has been shown that the removal of the metals by metal-chelating process causes some problems of toxicity due to the induced charge change [19]. But the examination of the literature demonstrates that the transition metal chelation of the titled ligands has not been done either experimentally or theoretically.

The goal of this work is to do a comprehensive density functional theory (DFT) study on the first-row transition metal (II) chelation by ADPHT derivatives, using both the neutral and mono deprotonated forms of ligands. We have studied the coordination abilities for the first-row transition metal (II) cations used $\left(\mathrm{Fe}^{2+}, \mathrm{Ni}^{2+}, \mathrm{Cu}^{2+}\right.$, and $\left.\mathrm{Zn}^{2+}\right)$. The authors evaluated the proton affinity (PA) of each complex and therefore analyzed the comparative impact of the metal chelation on the antioxidant activities. The proton affinity free energy (PAFE) has also been taken into account. The metal interaction is further studied on the basis of NBO charges. The replacement of $\mathrm{M}^{2+}$ by the $\mathrm{M}^{+}$leads to the evaluation of the influence of the metal charge on analyzed properties. For this last point, the authors have considered only the copper atom as metal. Estimation of the effect of solvents (water, benzene, and N,N-dimethylformamide $(\mathrm{DMF}))$ on the calculated structural parameters has also been done.

\section{Computational Details and Theoretical Background}

2.1. Computational Details. All calculations were performed using Gaussian 09 program package [20]. The optimization of gas-phase structure of each molecular system was obtained using DFT method with B3LYP [21] functional. For $\mathrm{M}^{2+}$ $\left(\mathrm{M}^{2+}=\mathrm{Fe}^{2+}, \mathrm{Ni}^{2+}, \mathrm{Cu}^{2+}\right.$, and $\left.\mathrm{Zn}^{2+}\right)$, the authors used the nonrelativistic effective core potential (ECP) LanL2DZ [22] for metal atom in combination with $6-31+G(d, p)$ for $C$, $\mathrm{N}, \mathrm{O}$, and $\mathrm{H}$ atoms. This generically made basis set is denoted as Mixed I. The importance of using ECPs for transition metal complexes has been emphasized by prior researches [23,24]. The geometry optimization is followed by vibrational frequency calculations. All of these calculations were carried out in vacuum and in three solvents (water, benzene, and DMF (N,N-dimethylformamide)). The integral equation formalism of the polarized continuum $[25,26]$ has been taken into account to analyze the solvent effect. To evaluate the influence of the basis set on geometries, an additional geometrical optimization of the gas-phase structures followed by frequency calculations using a new mixed basis set $\left[\mathrm{M}^{2+}\left(\mathrm{Fe}^{2+}, \mathrm{Ni}^{2+}, \mathrm{Cu}^{2+}\right.\right.$, and $\left.\mathrm{Zn}^{2+}\right)=6-31 \mathrm{G}(\mathrm{d})$ and $6-31+\mathrm{G}(\mathrm{d}, \mathrm{p})=\mathrm{C}, \mathrm{N}, \mathrm{O}$, and $\mathrm{H}]$ subsequently denoted as Mixed II has been achieved.

\subsection{Theoretical Background}

2.2.1. Thermodynamic Energies of Coordination Abilities and Deprotonation of Complexes. The coordination ability of various cations $\left(D_{e}\right)$ (dissociation energy of the complex noted $c$ ) is defined according to (1):

$$
D_{e}=E_{c}-\left(E_{l}+E_{m}\right)
$$

$E_{c}, E_{l}$, and $E_{m}$ are, respectively, the energy of the complex, ligand, and metal. Firstly, $D_{e}$ values are estimated after geometrical optimization calculations at B3LYP/Mixed I in the gas-phase and in various solvents and reevaluated at B3LYP/Mixed II level in the gas-phase Single-point calculations at the CCSD (T) have been carried out to reproduce the gas-phase $D_{e}$. The levels of theory have shown to reproduce satisfactorily the first-row transition metal binding energy of glycine and its derivatives $[27,28]$. The Metal Ion Affinity (MIA) [29, 30] was assumed to be the negative of the reaction enthalpy $\left(\Delta H_{298}^{0}\right)$ defined in (2). We have determined the complexation free energy according to (3):

$$
\begin{aligned}
\text { MIA } & =-\Delta H_{298}^{0}=-\left[H_{298 c}^{0}-\left(H_{298 l}^{0}+H_{298 m}^{0}\right)\right] \\
\Delta G_{298}^{0} & =G_{298 c}^{0}-\left(G_{298 l}^{0}+G_{298 m}^{0}\right) .
\end{aligned}
$$

2.2.2. NBO Analysis. The stabilization energy $E_{2}$ associated with $i \rightarrow j$ delocalization for a donor $\mathrm{NBO}(i)$ and an acceptor $\mathrm{NBO}(j)$ is calculated according to

$$
E_{2}=q_{i j} \frac{F^{2}(i, j)}{\varepsilon_{j}-\varepsilon_{i}},
$$

where $q_{i j}$ represents the $i$ th donor orbital occupancy and $\varepsilon_{i}$ and $\varepsilon_{j}$ are diagonal elements and $F(i, j)$ off-diagonal elements, respectively, linked to NBO Fock matrix [31]. 
The thermodynamic energies (proton affinity (PA) and proton affinity fee energy (PAFE)) relative to the deprotonation of each optimized complex are determined as follows:

$$
\begin{aligned}
{[M L H]^{n+} \longrightarrow } & {[M L]^{(n-1)+}+H^{+} } \\
\mathrm{PA}= & H\left(H^{+}\right)+H\left(\left[M L^{(n-1)+}\right]\right) \\
& -H\left(\left[M L H^{n+}\right]\right) \\
\text { PAFE }= & G\left(H^{+}\right)+G\left(\left[M L^{(n-1)+}\right]\right) \\
& -G\left(\left[M L H^{n+}\right]\right) .
\end{aligned}
$$

$[M L H],[M L]^{+}$, and $H^{+}$are, respectively, complex and deprotonated complexes and the proton. $H(Y)$ is the enthalpy of species $Y\left(Y=M L H, M L^{+}\right.$, and $\left.H^{+}\right)$. Solvent contribution was determined using an integral equation continuum model (IEF-PCM) method $[25,26]$.

2.2.3. Atoms in Molecules Analysis Theory. The Quantum Theory of Atom in Molecules (QTAIM) proposed by Bader [32] performed as implemented in Multiwfn [33] was to analyze the nature of all metal-ligand bonds. A logical approximation of their relative energies eases the specification of the original nature of metal-ligand bonds. The indicators of metal-ligand bond used are the electron densities $\rho(r)$ and their Laplacians $\nabla^{2} \rho(r)$ calculated at the bond critical points (BCPs). The local kinetic electron energy density and the potential energy density $v(r)$ are then defined, respectively, in (8) and (9) $[32,34]$. Consider

$$
\begin{aligned}
G(r) & =\frac{3}{10}(3 \pi)^{2 / 3} \rho(r)^{5 / 3}+\frac{1}{6} \nabla^{2} \rho(r) \\
\nu(r) & =\frac{\hbar^{2}}{4 m} \nabla^{2} \rho(r)-2 G(r) .
\end{aligned}
$$

According to the sign of the Laplacian of the electron density $\left(\nabla^{2} \rho(r)\right)$, the metal-ligand interactions are covalent and electrostatic, if $\nabla^{2} \rho(r)$ are, respectively, negative and positive. A further instrument for estimation of the nature of the metal-ligand is the fraction $-G(r) / \nu(r)$. From this descriptor, the metal-ligand bond is noncovalent or partly covalent in nature, if $-G(r) / \nu(r)>1$ and $0.5<-G(r) / \nu(r)<1$, respectively. This ration combined with the electron density $\left(\nabla^{2} \rho(r)\right)$ is useful to analyze the intermediate interactions and closed shell interaction: $\left(-G(r) / \nu(r)<1\right.$ and $\left.\nabla^{2} \rho(r)<0\right)$ ) and $\left(-G(r) / \nu(r)>1\right.$ and $\left.\left.\nabla^{2} \rho(r)<0\right)\right)$, respectively.

This analysis is using B3LYP/Mixed II optimized structures in the gas-phase. QTAIM analysis was then performed as implemented in Multiwfn [32].

\section{Results and Discussion}

We have optimized the M-ADPHT complexes using all the possible coordination modes. These optimizations yield a unique coordination mode $\left(\mathrm{O}_{3}, \mathrm{O}_{2}\right)$ as shown in Figure 1 for neutral or deprotonated ADPHT derivatives.
3.1. Geometrical Details. All the structures have been optimized without any symmetric constraint. The relevant geometrical parameters of M-ADPHT complexes with neutral ligands, labeled according to convention given in Figure 1, are compiled in Table 1. The optimization generally yields $\mathrm{M}-\mathrm{O}_{2}$ bond distances longer, compared to those of $\mathrm{M}-\mathrm{O}_{3}$ bonds. The bond length difference was in the following range: 0.009-0.077 $\AA$. We attributed such a difference to the fact that the $\mathrm{C}_{3}=\mathrm{O}_{3}$ carbonyl group is connected to two $\mathrm{N}_{1}$ and $\mathrm{N}_{2}$ nitrogen atoms. The induced cumulative electron donating effect of these two neighboring nitrogen atoms then increases the electron density around the $\mathrm{O}_{3}$ oxygen atom. This atom is consequently more nucleophile than the $\mathrm{O}_{2}$ homolog which is near only one $\mathrm{N}_{3}$ nitrogen atom. Our results showed that the $\mathrm{M}-\mathrm{O}_{i}(i=2,3)$ decreased slightly with the substitution of the hydrogen by donor alkyl group $\left(\mathrm{R}=\mathrm{CH}_{3}, \mathrm{C}_{2} \mathrm{H}_{5}\right)$. Independently of the substituent, the $\mathrm{Cu}-\mathrm{O}_{i}(i=2,3)$ distances are the longest in gas-phase. The replacement of $\mathrm{Cu}^{2+}\left(\mathrm{d}^{9}\right)$ by $\mathrm{Cu}^{+}\left(\mathrm{d}^{10}\right)$ leads to the shortening of $\mathrm{Cu}-\mathrm{O}_{2}$ bond lengths but also to the lengthening of $\mathrm{Cu}-\mathrm{O}_{3}$ bond distances. This fact originates predominantly from the interaction between the doubly occupied metal $3 \mathrm{~d}$ orbital and the lone pairs of donor oxygen atoms, which significantly increases the metalligand repulsion in the $\mathrm{Cu}^{+}\left(\mathrm{d}^{10}\right)$-complexes. This does not occur for $\mathrm{Cu}^{2+}\left(\mathrm{d}^{9}\right)$ for which the $3 \mathrm{~d}$ orbital remains singly occupied. Our results on $\mathrm{Cu}^{+}\left(\mathrm{d}^{10}\right)$-complexes are in line with similar theoretical works on monovalent metal cation $\left(\mathrm{Co}^{+}\right.$, $\mathrm{Ni}^{+}$, and $\mathrm{Cu}^{+}$)-ligands (glycine [35], water [35, 36], ammonia $[37,38]$, and adenine [39]) complexes. We concluded that this metal-ligand repulsion in $\mathrm{Cu}^{+}\left(\mathrm{d}^{10}\right)$-complexes is more pronounced for the more nucleophile oxygen atom $\mathrm{O}_{3}$. The comparison of the bond distances of $\mathrm{Cu}^{+}$-complexes with those of $\mathrm{Cu}^{2}$-complexes (Table 1) reveals the fact that the effects of this substitution are only limited to metal-ligand bond distances. The dissimilarity observed between distances of bonds of ADPHT complexes and those of isolated ligand displays the significant activation of adjacent bonds by the metal cation. For instance, the metal chelation of ligand a by $\mathrm{Cu}^{2+}$ augments the $\mathrm{C}_{3}-\mathrm{O}_{3}$ bond distance from 1.216 to $1.250 \AA$.

The optimized $\mathrm{O}_{2}-\mathrm{M}^{2+}-\mathrm{O}_{3}$ angle in all $\mathrm{M}^{2+}$-complexes in gas-phase varies from 98.3 to $106.4^{\circ}$. The dihedral angles $\Phi$ $\left[\mathrm{N}_{3}-\mathrm{C}_{2}-\mathrm{O}_{2}-\mathrm{M}^{2+}\right]$ and $\Phi\left[\mathrm{N}_{1}-\mathrm{N}_{3}-\mathrm{C}_{2}-\mathrm{O}_{2}\right]$ were, respectively, in the following range: $-57.3-59.1$ and $-35.6-53.3^{\circ}$. This fact renders chelate rings of M-ADPHT $\left(\mathrm{M}=\mathrm{Fe}^{2+}, \mathrm{Ni}^{2+}\right.$, and $\left.\mathrm{Cu}^{2+}\right)$ nonplanar. In addition, the values obtained for the dihedral angles $\Phi\left[\mathrm{N}_{1}-\mathrm{N}_{3}-\mathrm{C}_{2}-\mathrm{O}_{2}\right]$ revealed that the $\mathrm{N}_{1}, \mathrm{~N}_{3}, \mathrm{C}_{2}$, and $\mathrm{O}_{2}$ atoms are not located in the same plane (Table 1). Our B3LYP data revealed that the benzene and 1,2,4-triazole ring remained planar (Figure $1 \mathrm{~S}$ ) in the supporting information, available online at https://doi.org/10.1155/2017/5237865). In the same vein, the calculated values of the dihedral angle $\Phi$ $\left[\mathrm{N}_{3}-\mathrm{C}_{2}-\mathrm{C}_{1}-\mathrm{C}_{5}\right]$ indicated the fact that the $\mathrm{C}_{5}$ atom is almost in the plane containing $\mathrm{N} 3, \mathrm{C}_{2}$, and $\mathrm{Cl}$ atoms, which is nearly perpendicular to the benzene ring.

Contrary to the results obtained in gas-phase, the optimization after the solvation of the molecular system yields $\mathrm{M}-\mathrm{O}_{3}$ bond distances longer, compared to those of $\mathrm{M}-\mathrm{O}_{2}$ 
TABLE 1: Selected B3LYP/Mixed I level: bond lengths (Á), bond angles (degree), and dihedral angles (degree) for neutral ADPHT ligand-metal complexes in various media.

\begin{tabular}{|c|c|c|c|c|c|c|c|c|c|c|c|c|c|c|c|}
\hline & & $\mathrm{Fe}^{2+}$ & & & $\mathrm{Ni}^{2+}$ & & & $\mathrm{Cu}^{2+}$ & & & $\mathrm{Cu}^{+}$ & & & $\mathrm{Zn}^{2+}$ & \\
\hline Parameters & la & $1 \mathrm{~b}$ & $1 c$ & $2 a$ & $2 \mathrm{~b}$ & $2 c$ & $3 a$ & $3 \mathrm{~b}$ & $3 c$ & $4 \mathrm{a}$ & $4 \mathrm{~b}$ & $4 c$ & $5 a$ & $5 b$ & $5 c$ \\
\hline \multicolumn{16}{|l|}{ gas } \\
\hline $\mathrm{M}^{2+}-\mathrm{O}_{2}$ & 1.840 & 1.836 & 1.835 & 1.837 & 1.836 & 1.835 & 2.061 & 2.046 & 2.040 & 1.998 & 1.999 & 1.999 & 1.906 & 1.906 & 1.905 \\
\hline $\mathrm{M}^{2+}-\mathrm{O}_{3}$ & 1.818 & 1.810 & 1.806 & 1.827 & 1.820 & 1.819 & 1.969 & 1.969 & 1.969 & 1.995 & 1.986 & 1.986 & 1.899 & 1.898 & 1.899 \\
\hline $\mathrm{O}_{2}-\mathrm{M}^{2+}-\mathrm{O}_{3}$ & 105.4 & 105.8 & 105.8 & 102.6 & 102.1 & 102.1 & 98.5 & 98.5 & 98.3 & 105.6 & 106.2 & 105.6 & 106.1 & 106.1 & 106.4 \\
\hline $\mathrm{N}_{1}-\mathrm{C}_{3}-\mathrm{O}_{3}-\mathrm{M}^{2+}$ & 27.2 & 24.5 & 23.4 & 54.4 & -57.3 & 57.9 & 57.4 & 59.1 & 59.0 & 51.1 & 51.6 & 53.4 & 42.7 & 44.9 & 45.5 \\
\hline $\mathrm{N}_{3}-\mathrm{C}_{2}-\mathrm{O}_{2}-\mathrm{M}^{2+}$ & 33.7 & 31.7 & 31.0 & 35.0 & -35.6 & 35.5 & 53.1 & 53.3 & 52.1 & 53.3 & 53.5 & 54.0 & 44.9 & 42.3 & 42.4 \\
\hline $\mathrm{N}_{1}-\mathrm{N}_{3}-\mathrm{C}_{2}-\mathrm{O}_{2}$ & 12.6 & 12.3 & 12.1 & 11.9 & -11.5 & 11.7 & 5.7 & 5.0 & 6.1 & 7.7 & 7.5 & 7.1 & 9.8 & 10.0 & 9.8 \\
\hline \multicolumn{16}{|l|}{ Water } \\
\hline $\mathrm{M}^{2+}-\mathrm{O}_{2}$ & 1.920 & 1.925 & 1.933 & 1.854 & 1.863 & 1.865 & 1.954 & 1.951 & 1.955 & 2.029 & 2.035 & 2.038 & 2.048 & 2.047 & 2.071 \\
\hline $\mathrm{M}^{2+}-\mathrm{O}_{3}$ & 1.929 & 1.916 & 1.932 & 1.838 & 1.829 & 1.835 & 1.933 & 1.927 & 1.928 & 2.022 & 2.016 & 2.019 & 2.032 & 2.055 & 2.023 \\
\hline $\mathrm{O}_{2}-\mathrm{M}^{2+}-\mathrm{O}_{3}$ & 99.7 & 98.2 & 97.8 & 97.9 & 98.3 & 98.2 & 101.0 & 99.7 & 99.8 & 103.5 & 102.9 & 102.3 & 90.7 & 91.1 & 91.3 \\
\hline $\mathrm{N}_{1}-\mathrm{C}_{3}-\mathrm{O}_{3}-\mathrm{M}^{2+}$ & 44.4 & 40.9 & 48.5 & 64.3 & -66.4 & 66.7 & 58.6 & 60.8 & 63.0 & 54.5 & 56.9 & 59.8 & 64.3 & 57.6 & 66.5 \\
\hline $\mathrm{N}_{3}-\mathrm{C}_{2}-\mathrm{O}_{2}-\mathrm{M}^{2+}$ & 47.5 & 50.9 & 54.1 & 22.8 & -36.0 & 37.2 & 43.8 & 44.6 & 47.6 & 60.6 & 61.5 & 61.8 & 63.2 & 66.1 & 62.0 \\
\hline $\mathrm{N}_{1}-\mathrm{N}_{3}-\mathrm{C}_{2}-\mathrm{O}_{2}$ & 14.1 & 14.4 & 11.4 & 13.4 & 52.0 & 10.1 & 13.6 & 14.6 & 11.4 & 5.7 & 4.2 & 3.2 & 1.0 & 5.0 & 1.0 \\
\hline \multicolumn{16}{|l|}{ Benzene } \\
\hline $\mathrm{M}^{2+}-\mathrm{O}_{2}$ & 1.865 & 1.868 & 1.871 & 1.833 & 1.843 & 1.841 & 2.042 & 2.019 & 2.018 & 2.012 & 2.018 & 2.018 & - & 1.944 & 1.949 \\
\hline $\mathrm{M}^{2+}-\mathrm{O}_{3}$ & 1.850 & 1.846 & 1.846 & 1.829 & 1.818 & 1.820 & 1.971 & 1.972 & 1.970 & 2.007 & 2.001 & 2.001 & - & 1.928 & 1.932 \\
\hline $\mathrm{O}_{2}-\mathrm{M}^{2+}-\mathrm{O}_{3}$ & 102.6 & 102.8 & 103.3 & 99.6 & 100.9 & 100.9 & 98.9 & 99.7 & 98.5 & 104.5 & 103.5 & 103.2 & - & 101.9 & 102.3 \\
\hline $\mathrm{N}_{1}-\mathrm{C}_{3}-\mathrm{O}_{3}-\mathrm{M}^{2+}$ & 131.8 & 32.9 & 35.4 & 59.9 & -58.5 & 59.8 & 58.3 & 59.2 & 61.3 & 52.7 & 55.9 & 57.5 & - & 42.5 & 48.4 \\
\hline $\mathrm{N}_{3}-\mathrm{C}_{2}-\mathrm{O}_{2}-\mathrm{M}^{2+}$ & 36.1 & 40.3 & 38.5 & 27.9 & -31.8 & 34.7 & 53.2 & 50.6 & 54.7 & 55.4 & 58.6 & 58.6 & - & 40.8 & 42.9 \\
\hline $\mathrm{N}_{1}-\mathrm{N}_{3}-\mathrm{C}_{2}-\mathrm{O}_{2}$ & 13.9 & 14.6 & 13.1 & 9.3 & -14.0 & 13.6 & 5.8 & 7.2 & 5.2 & 9.8 & 4.6 & 4.7 & - & 13.6 & 9.7 \\
\hline \multicolumn{16}{|l|}{$D M F$} \\
\hline $\mathrm{M}^{2+}-\mathrm{O}_{2}$ & 1.918 & 1.923 & 1.909 & 1.852 & 1.861 & 1.857 & 1.958 & 1.955 & 1.958 & 2.028 & 2.034 & 2.037 & 2.043 & 2.050 & 2.058 \\
\hline $\mathrm{M}^{2+}-\mathrm{O}_{3}$ & 1.926 & 1.912 & 1.902 & 1.837 & 1.828 & 1.828 & 1.937 & 1.930 & 1.931 & 2.021 & 2.015 & 2.019 & 2.027 & 2.042 & 2.003 \\
\hline $\mathrm{O}_{2}-\mathrm{M}^{2+}-\mathrm{O}_{3}$ & 99.6 & 116.8 & 100.2 & 98.1 & 98.4 & 98.4 & 101.0 & 100.9 & 99.8 & 103.6 & 103.0 & 102.2 & 90.9 & 91.0 & 91.4 \\
\hline $\mathrm{N}_{1}-\mathrm{C}_{3}-\mathrm{O}_{3}-\mathrm{M}^{2+}$ & 42.4 & 50.0 & 38.4 & 63.9 & -66.2 & 65.7 & 58.3 & 60.5 & 62.9 & 54.4 & 56.9 & 59.8 & 64.0 & 57.6 & 62.8 \\
\hline $\mathrm{N}_{3}-\mathrm{C}_{2}-\mathrm{O}_{2}-\mathrm{M}^{2+}$ & 48.1 & 40.4 & 39.9 & 23.5 & -35.6 & 34.8 & 44.4 & 44.8 & 47.7 & 60.5 & 61.0 & 61.6 & 63.1 & 65.8 & 64.2 \\
\hline $\mathrm{N}_{1}-\mathrm{N}_{3}-\mathrm{C}_{2}-\mathrm{O}_{2}$ & 13.6 & 14.6 & 16.6 & 13.5 & -9.5 & 9.7 & 13.3 & 14.5 & 11.3 & 5.6 & 4.5 & 3.3 & 1.0 & 5.0 & 3.0 \\
\hline
\end{tabular}

bonds especially for complex la in benzene and DMF. One can observe that the variations of the geometrical parameters are very versatile in solution-phase.

To investigate the contribution of the metal chelation to the antioxidant activity of ADPHT derivatives, we analyzed the $\mathrm{X}-\mathrm{H}$ bond distances $\left(\mathrm{X}=\mathrm{N}_{3}, \mathrm{~N}_{2}\right.$, and $\left.\mathrm{C}_{1}\right)$ of the structures obtained and compared them with those of isolated ligands. From Figure 2S, one can find out that the metal chelation slightly increases the $\mathrm{X}-\mathrm{H}$ bond distances, then decreases the bond dissociation energies of these bonds, and therefore enhances the antioxidant activities. In M-ADPHT complexes optimized, the longer $\mathrm{X}-\mathrm{H}$ bond distances are obtained for $\mathrm{C}_{1}-\mathrm{H}_{1}$ bonds due to the captodative stabilization evoked in our previous work [18]. Figure $3 \mathrm{~S}$ displays the fact that the solvation of complexes induces an important reduction of the $\mathrm{C}_{1}-\mathrm{H}_{1}$ bond distances. Such a reduction is more pronounced for $\mathrm{Cu}^{2+}$-complexes in benzene and DMF.

Geometrical parameters of optimized complexes obtained in gas-phase from deprotonated ligands (Tables 1-3S in the supporting information) illustrated the fact that the metal-ligand distances are lower than those of complexes resulting from neutral ligand, with the exception of $8 \mathrm{~A}$ complex. The main justification of this exception resulted from the optimization of $8 \mathrm{~A}$ complex that leads to a monodental structure with the $\mathrm{O}_{3}$ oxygen only effectively binded to the $\mathrm{Cu}^{2+}$ cation. Our results also showed that the $\mathrm{M}-\mathrm{O}_{3}$ bond distances are slightly longer than those of $\mathrm{M}-\mathrm{O}_{2}$ bonds. This is basically due to the nearness of the $\mathrm{C}_{2}=\mathrm{O}_{2}$ carbonyl group to proton abstraction site $\left(\mathrm{N}_{3}\right.$ atom $)$ that subsequently increases the electron density around the $\mathrm{O}_{2}$ oxygen atom. Contrary to previous remarks on complexes obtained from neutral ligands, the latter becomes now more nucleophile than the $\mathrm{O}_{3}$ oxygen atom.

Figure 2 indicates that the $\mathrm{M}^{2+}-\mathrm{O}_{i}(i=2,3)$ bond distances yielded by B3LYP/Mixed II are shorter than that relative to B3LYP/Mixed I. The bond distance differences obtained are in the ranges $0.023-0.887$ and $0.019-0.169 \AA$, respectively, for $\mathrm{M}^{2+}-\mathrm{O}_{2}$ and $\mathrm{M}^{2+}-\mathrm{O}_{3}$ bond. This fact can be attributed to the fact that the valence orbitals are not properly described by B3LYP/Mixed I. This results from the 

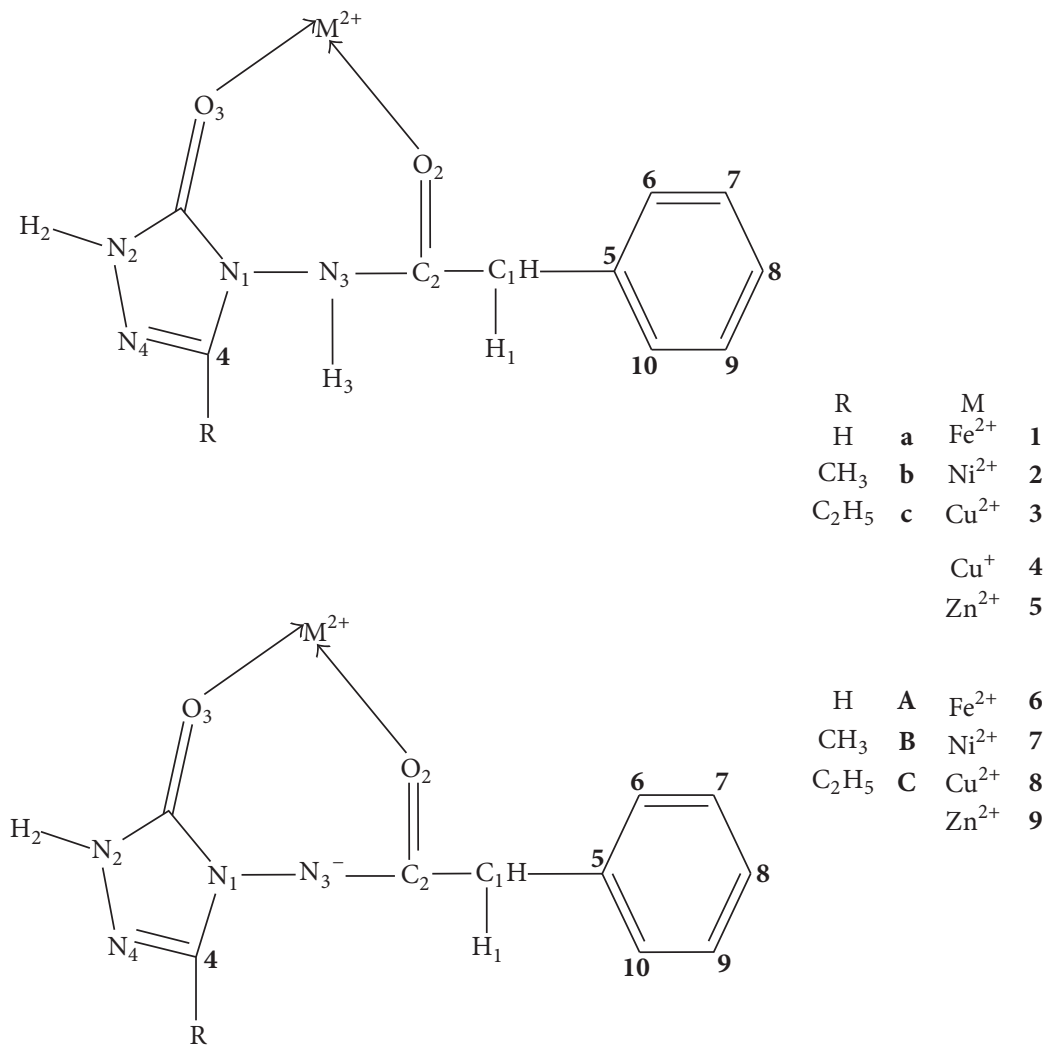

$\begin{array}{llll}\mathrm{H} & \mathbf{A} & \mathrm{Fe}^{2+} & \mathbf{6}\end{array}$

$\begin{array}{llll}\mathrm{CH}_{3} & \text { B } & \mathrm{Ni}^{2+} & 7\end{array}$

$\mathrm{C}_{2} \mathrm{H}_{5} \quad \mathbf{C} \quad \mathrm{Cu}^{2+} \mathbf{8}$

$\mathrm{Zn}^{2+} 9$

FIGURE 1: Schematic representation of M-ADPHT complexes including the adopted numbering system used.
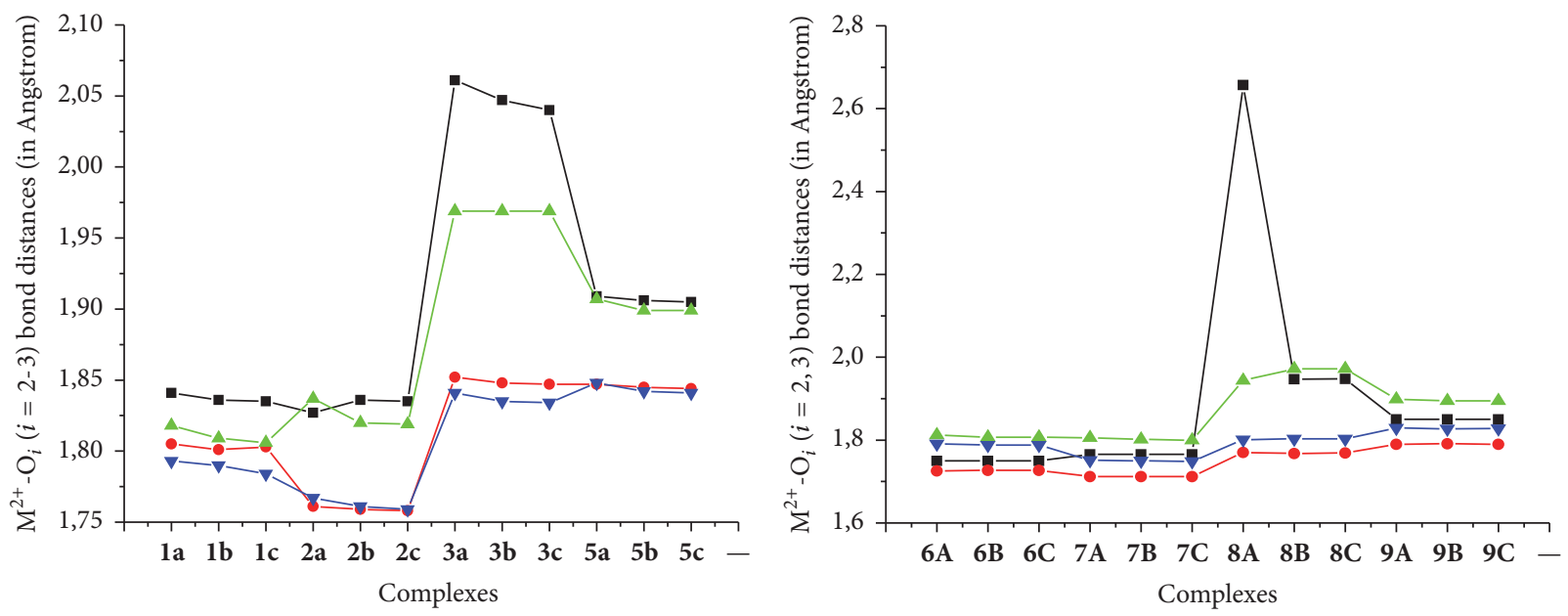

$-\mathrm{M}^{2+}-\mathrm{O}_{2}(\mathrm{~B} 3 \mathrm{LYP} /$ Mixed I)

$\rightarrow \mathrm{M}^{2+}-\mathrm{O}_{2}$ (B3LYP/Mixed II)

$\rightarrow \mathrm{M}^{2+}-\mathrm{O}_{3}(\mathrm{~B} 3 \mathrm{LYP} /$ Mixed I)

$\rightarrow \mathrm{M}^{2+}-\mathrm{O}_{3}$ (B3LYP/Mixed II)

- $\mathrm{M}^{2+}-\mathrm{O}_{2}$ (B3LYP/Mixed I)

$\rightarrow \mathrm{M}^{2+}-\mathrm{O}_{3}$ (B3LYP/Mixed I)

$\rightarrow \mathrm{M}^{2+}-\mathrm{O}_{2}(\mathrm{~B} 3 \mathrm{LYP} /$ Mixed II)

$\rightarrow \mathrm{M}^{2+}-\mathrm{O}_{3}($ B3LYP/Mixed II)

(a)

(b)

FIGURE 2: Superposition of $\mathrm{M}^{2+}-\mathrm{O}_{i}$ bond obtained using B3LYP/Mixed I, B3LYP/Mixed II, and CCSD(T) for neutral ADPHT ligands (a) and for deprotonated ADPHT ligands (b). 
TABLE 2: Values (in kJ/mol) of metal binding energy $\left(D_{e}\right)$, metal binding enthalpy $\left(\Delta H_{298}^{0}\right)$, and metal binding free energy $\left(\Delta G_{298}^{0}\right)$ for $\operatorname{ADPHT}$ ligand-metal complexes in various media used at B3LYP/Mixed I level.

\begin{tabular}{|c|c|c|c|c|c|c|c|c|c|c|c|}
\hline & & \multicolumn{2}{|c|}{$\mathrm{Fe}^{2+}$} & \multicolumn{2}{|c|}{$\mathrm{Ni}^{2+}$} & \multicolumn{2}{|c|}{$\mathrm{Cu}^{2+}$} & \multicolumn{2}{|c|}{$\mathrm{Cu}^{+}$} & \multicolumn{2}{|c|}{$\mathrm{Zn}^{2+}$} \\
\hline & & 1a & $6 A$ & $2 a$ & $7 \mathrm{~A}$ & $3 a$ & $8 \mathrm{~A}$ & $4 a$ & $9 A$ & $5 a$ & $10 \mathrm{~A}$ \\
\hline \multirow{4}{*}{$D_{e}$} & Gas & -1194 & -2081 & -1282 & -2158 & -1215 & -2112 & -309 & -756 & -904 & -1752 \\
\hline & Water & -277 & -435 & -267 & -443 & -421 & -642 & -121 & -211 & -57 & -177 \\
\hline & Benzene & -642 & -1095 & -681 & -1172 & -757 & -1284 & -201 & -451 & - & -819 \\
\hline & DMF & -287 & -484 & -280 & -467 & -432 & -664 & -124 & -219 & -62 & -196 \\
\hline \multirow{4}{*}{$\Delta H_{298}^{0}$} & Gas & -1196 & -2083 & -1285 & -2160 & -1218 & -2114 & -312 & -759 & -907 & -1754 \\
\hline & Water & -279 & -438 & -270 & -446 & -424 & -645 & -124 & -214 & -59 & -179 \\
\hline & benzene & -644 & -1097 & -683 & -1174 & -759 & -1287 & -204 & -453 & - & -821 \\
\hline & $\mathrm{DMF}$ & -289 & -486 & -282 & -469 & 434 & -666 & -126 & -222 & -68 & -198 \\
\hline \multirow{5}{*}{$\Delta G_{298}^{0}$} & Gas & -1152 & -2043 & -1182 & -2121 & -274 & -2072 & -1242 & -722 & -864 & -1714 \\
\hline & Water & -236 & -396 & -384 & -405 & -88 & -605 & -227 & -180 & -13 & -140 \\
\hline & benzene & -598 & -1058 & -719 & -1132 & -165 & -1245 & -634 & -416 & - & -778 \\
\hline & DMF & -246 & -446 & -395 & -428 & -91 & -629 & -240 & -187 & -21 & -159 \\
\hline & & $1 b$ & $6 B$ & $2 \mathbf{b}$ & $7 \mathrm{~B}$ & $3 \mathbf{b}$ & $8 B$ & $4 \mathrm{~b}$ & 9B & $5 \mathbf{b}$ & $10 \mathrm{~B}$ \\
\hline \multirow{4}{*}{$D_{e}$} & Gas & -1219 & -2093 & -1304 & -2169 & -1231 & -2063 & -318 & -758 & -926 & -1763 \\
\hline & Water & -274 & -383 & -269 & -448 & -422 & -606 & -119 & -211 & -56 & -825 \\
\hline & Benzene & -653 & -1138 & -691 & -1180 & -764 & -1241 & -204 & -452 & -382 & - \\
\hline & DMF & -285 & -459 & -282 & -471 & -433 & -628 & -122 & -219 & -64 & - \\
\hline \multirow{4}{*}{$\Delta H_{298}^{0}$} & Gas & -1222 & -2095 & -1307 & -2171 & -1233 & -2066 & -320 & -760 & -929 & -1765 \\
\hline & Water & -277 & -385 & -272 & -450 & -425 & -609 & -121 & -213 & -58 & - \\
\hline & Benzene & -656 & -1141 & -694 & -1183 & -767 & -1243 & -207 & -455 & -385 & -828 \\
\hline & DMF & -288 & -461 & -284 & -474 & -435 & -630 & -124 & -222 & -67 & - \\
\hline \multirow{5}{*}{$\Delta G_{298}^{0}$} & Gas & -1177 & -2053 & -1199 & -2130 & -283 & -2029 & -1265 & -721 & -887 & -1726 \\
\hline & Water & -233 & -344 & -382 & -409 & -85 & -578 & -228 & -179 & -15 & - \\
\hline & Benzene & -608 & -1103 & -728 & -1144 & -171 & -1211 & -647 & -421 & -334 & -789 \\
\hline & DMF & -244 & -414 & -392 & -427 & -88 & -595 & -240 & -182 & -24 & - \\
\hline & & lc & $6 \mathrm{C}$ & $2 \mathrm{c}$ & $7 \mathrm{C}$ & $3 c$ & $8 \mathrm{C}$ & $4 \mathrm{c}$ & $9 \mathrm{C}$ & $5 c$ & $10 \mathrm{C}$ \\
\hline \multirow{4}{*}{$D_{e}$} & Gas & -1226 & -2093 & -1310 & -2168 & -1234 & -2061 & -317 & -755 & -933 & -1764 \\
\hline & Water & -274 & - & -264 & -444 & -417 & -602 & -114 & -207 & -53 & -175 \\
\hline & Benzene & -655 & -1140 & -692 & -1179 & -761 & -1239 & -202 & -451 & -383 & -825 \\
\hline & DMF & -282 & -485 & -281 & -467 & -427 & -6024 & -117 & -215 & -62 & -194 \\
\hline \multirow{4}{*}{$\Delta H_{298}^{0}$} & Gas & -1229 & 2096 & -1312 & -2170 & -1237 & -2063 & -319 & -757 & -936 & -1766 \\
\hline & Water & -277 & - & -266 & -446 & -420 & -604 & -117 & -210 & -55 & -177 \\
\hline & Benzene & -658 & -1142 & -695 & -1181 & -764 & -1241 & -204 & -453 & -385 & -827 \\
\hline & DMF & -284 & -487 & -267 & -470 & -430 & -629 & -119 & -218 & -65 & -197 \\
\hline \multirow{4}{*}{$\Delta G_{298}^{0}$} & Gas & -1182 & -2055 & -1201 & -2129 & -280 & -2027 & -1268 & -718 & -893 & -1728 \\
\hline & Water & -231 & - & -376 & -404 & -76 & -573 & -219 & -173 & -14 & -137 \\
\hline & Benzene & -608 & -1103 & -722 & -1142 & -163 & -1209 & -642 & -416 & -335 & -790 \\
\hline & DMF & -240 & -446 & -385 & -428 & -79 & -594 & -239 & -181 & -22 & -158 \\
\hline
\end{tabular}

poor description of the electron-electron repulsion. In the whole, higher differences are obtained for $\mathrm{Cu}^{2+}$-complexes for both ligands.

3.2. Metal Binding Selectivity. Table 2 gives the B3LYP/Mixed I complexation energies of the M-ADPHT complexes in various media. All the complexation energies are highly negative showing that the reaction is highly exothermic. One can observe a relevant decrease of the binding energies when passing from the gas-phase to solvent-phases. This drop is directly attributed to solvent effect that hampers the interaction between transition metal cation and ADPHT ligand. This diminution is more pronounced for protic solvents (water and DMF).

The complexation energies for solvent-phase are correlated to $\mathrm{M}-\mathrm{O}_{i}(i=2,3)$ bond distances presented in the previous section. Figure 3 and Table 2 display for neutral ligands ( $\mathbf{a}, \mathbf{b}$, and $\mathbf{c})$ an increasing binding selectivity in the following order: $\mathrm{Zn}^{2+}<\mathrm{Fe}^{2+}<\mathrm{Cu}^{2+}<\mathrm{Ni}^{2+}$. This is in line with the previous works which exhibited the highest affinity 


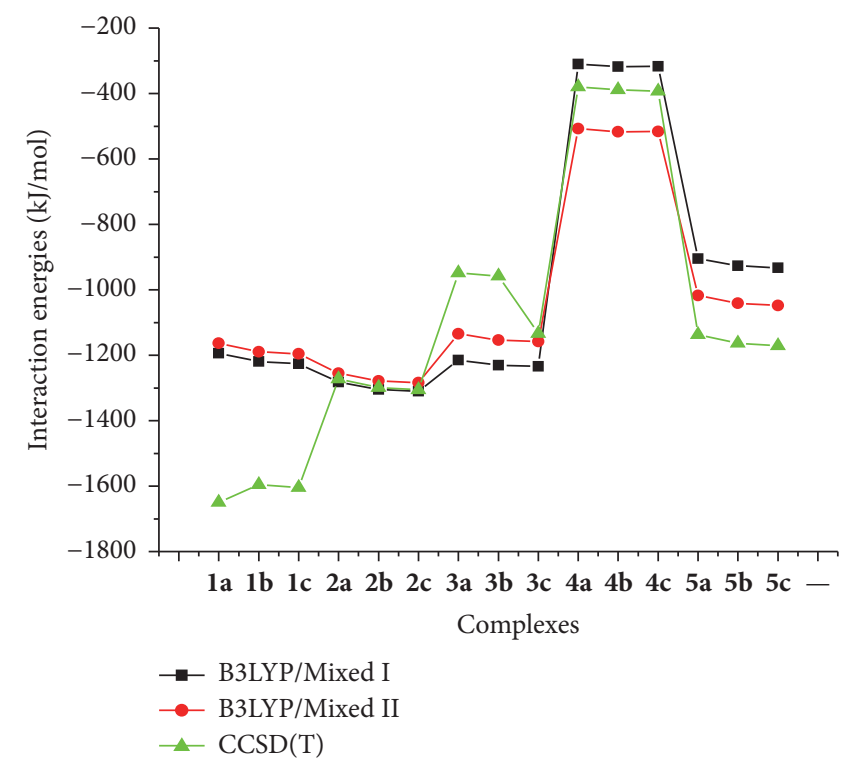

(a)

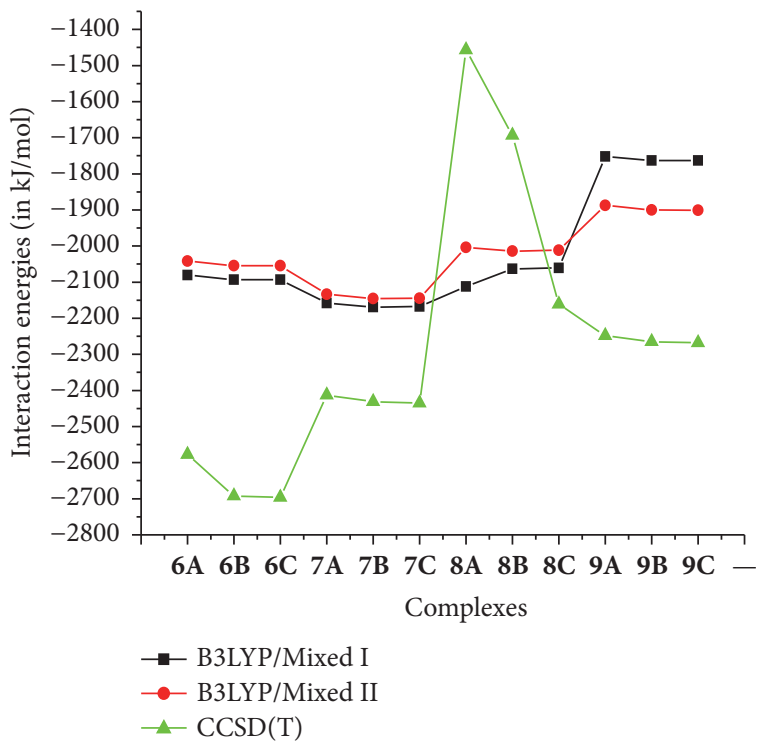

(b)

Figure 3: Superposition of metal binding energy values (in kJ/mol) obtained using B3LYP/Mixed I, B3LYP/Mixed II, and CCSD(T) for neutral ADPHT ligands (a) and for deprotonated ADPHT ligands (b).

of $\mathrm{Ni}^{2+}$ compared to other divalent first-row transition metal cations for glycine, glycine derivatives [40], polyether [41], and polyamine ligand [41]. The $\mathrm{M}^{2+}$-ADPHT complexes have higher metal ion affinities than the $\mathrm{Cu}^{+}$-ADPHT complexes. For both complexes, the higher binding abilities are obtained for $\mathrm{c}$ neutral ligand.

Our data show that the deprotonation of the ligand increases the binding affinity independently of the metal cation used. From Table 2, it is revealed that the binding energy difference between the value obtained from neutral ligand and that from deprotonated ones is in the following ranges: $827-897 \mathrm{kj} / \mathrm{mol}$ for $\mathrm{M}^{2+}$-ADPHT and $438-447 \mathrm{kj} / \mathrm{mol}$ for $\mathrm{Cu}^{+}$-ADPHT in gas-phase. The calculated trend for $D_{e}$ is in agreement with the notable decrease of ${\mathrm{M}-\mathrm{O}_{i}(i=}=$ $2,3)$ bond distances of optimized complexes obtained in gas-phase from deprotonated ligands evoked in previous section (Figure 2 and Tables $1-3 S$ in the supporting information). This increase of binding affinity is also observed in solution-phase. For the deprotonated ligand A, a similar increasing binding selectivity is observed compared to that of neutral ligand, whereas Figure 3 clearly reveals that the B3LYP/Mixed I complexation energies of the divalent ion with deprotonated ligands ( $\mathrm{B}$ and $\mathrm{C}$ ) follow the order of $\mathrm{Zn}^{2+}<\mathrm{Cu}^{2+}<\mathrm{Fe}^{2+}<\mathrm{Ni}^{2+}$. A similar situation was found for B3LYP/Mixed II values. In the whole, the latter is higher than the former for divalent transition cations with the exception of $\mathrm{Zn}^{2+}$-complexes. The average difference reached 6.2 and $67.0 \mathrm{~kJ} / \mathrm{mol}$, respectively, for neutral ADPHT $-\mathrm{M}^{2+}$ complexes and deprotonated ADPHT $-\mathrm{M}^{2+}$ complexes. For neutral ADPHT $-\mathrm{Cu}^{+}$complexes, Figure 3 also displays the drastic drop that is in $197.3-199.7 \mathrm{~kJ} / \mathrm{mol}$. In the same vein, difference in complexation energy values in the range $100.5-641.4 \mathrm{~kJ}$ is observed for deprotonated ADPHT
$-\mathrm{M}^{2+}$ complexes when passing from B3LYP calculations to $\operatorname{CCSD}(\mathrm{T})$ ones (Figure 3). This similar larger difference has been found by Constantino et al. in the theoretical study on interactions of $\mathrm{Co}^{+}$and $\mathrm{Co}^{2+}$ with glycine [35]. We attributed this fact to a bad annulment of self-interaction term by the exchange functional that leads to overstabilization of molecular systems by density functional methods. For neutral ADPHT $-\mathrm{M}^{2+}$ complexes, this difference is variable. In the case of $\mathrm{Ni}^{2+}$-complexes, differences are in a very narrow range of $4.4-9.5 \mathrm{~kJ} / \mathrm{mol}$ for calculations related to B3LYP/Mixed II.

The calculated interaction enthalpies presented in Table 2 do not give any additional relevant information on the metal binding selectivity. In order to get a deep insight into the capacity of ADPHT ligands to be bound to metal cations, we have calculated the interaction free energies. The calculated results obtained in various media inserted in Table 2 are negative showing that the formation of $\mathrm{M}^{n+}$-ADPHT complexes $(n=1,2)$ is spontaneous. A comparison of the interaction free energies of $\mathrm{Cu}^{2+}$ and $\mathrm{Cu}^{+}$in various media shows that the preference of both metal cations depends on the nature of the ADPHT ligands.

We note that higher capacity of the neutral ligand to bind to $\mathrm{Cu}^{+}$cation is observed. Contrary to monovalent copper cation, higher capacity is attributed to complexation of deprotonated ligand to $\mathrm{Cu}^{2+}$. We find again that our results indicate that all divalent metal cations prefer to be bound to deprotonated ADPHT ligands. In gas-phase, the lower interaction free energies obtained for $\mathrm{Ni}^{2+}$-ADPHT complexes confirms the preference of both ligands to bind to $\mathrm{Ni}^{2+}$ previously evoked in this section.

3.3. Electronic Structure and Atoms in Molecules Analysis. In previous studies, it has been found that the HOMO-LUMO 
HOMO

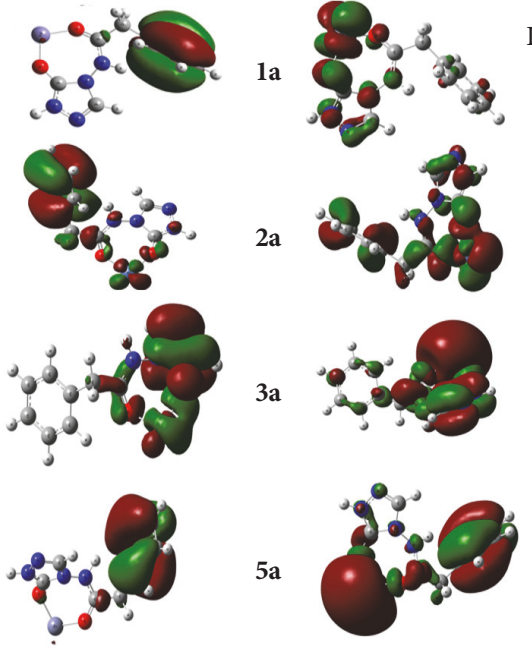

(a)
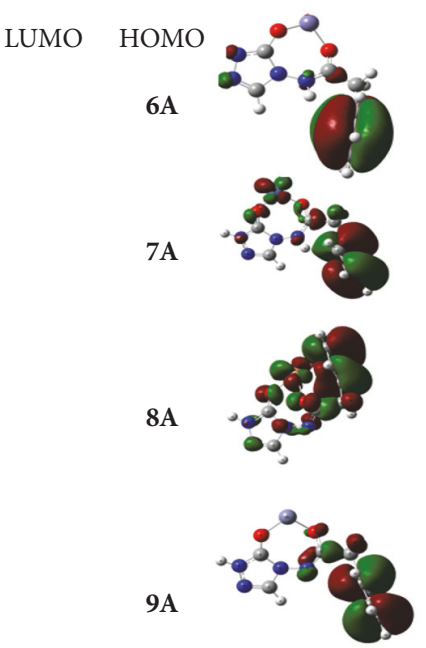

LUMO

$6 \mathrm{~A}$

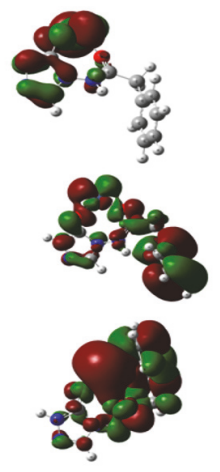

9A

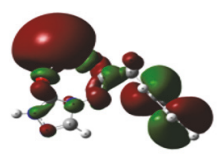

(b)

Figure 4: Schematic representation of frontier molecular orbitals of M-ADPHT complexes $(\mathrm{R}=\mathrm{H})$ : neutral ligand-divalent metal cation complexes (a) and deprotonated ligand-divalent metal cation complexes (b).

energy gap is an important stability descriptor [41-44]. The large HOMO-LUMO energy gap is consistent to stable and little reactive systems, but, in the contradictory case, the little stable systems correspond to highly reactive systems. The orbital frontier eigenvalues and HOMO-LUMO gaps of different complexes calculated in various media are inserted in Table 3. Our data reveal that deprotonated ADPHT ligand$\mathrm{M}^{2+}$ complexes are the most stable ones in gas-phase. The highest HOMO-LUMO energy gap matches up with the monodental complex $8 \mathrm{~A}$ in the same medium. This explains why the electron cloud of HOMO is mainly localized on atoms of benzyl rings and on the metal atom for complex 8A (see Figure 4). On the contrary, for other complexes, this cloud is exclusively located on atoms of benzyl ring. The solvation studied enhances the stability of the complexes studied. This enhancement is more pronounced for protic solvent (water and DMF). The comparison between the HOMO-LUMO gap on isolated ligands (Table $4 \mathrm{~S}$ in the supporting information) and that of complexes reveals that the metal chelation of isolated ligands reduces their stabilities independently of the medium.

The HOMO eigenvalues are used to characterize the donating ability of the molecule. Higher value of HOMO energy indicates a predisposition of the molecular system to loss electrons [45]. Higher value of HOMO energy is therefore an indication of the higher antioxidant activity [46].

In gas-phase, the values of HOMO energy of the isolated ligands (Table $4 S$ in the supporting information) exhibit $E_{\mathrm{c}}>$ $E_{\mathrm{b}}>E_{\mathrm{a}}$ for neutral ligands and $E_{\mathrm{B}}>E_{\mathrm{C}}>E_{\mathrm{A}}$ for deprotonated ones. One can then conclude that the orders for the antioxidant activity of these ADPHT ligands are $\mathrm{c}>\mathrm{b}>\mathrm{a}$ and $\mathrm{B}>\mathrm{C}>\mathrm{A}$, respectively, for neutral ligands and deprotonated homologs. For the former, this order remains invariable upon chelation with a metal ion with exception made to $\mathrm{Ni}^{2+}$ (c $=\mathrm{b}>\mathrm{a}$ ) in gas-phase. For the latter, the complexation of the deprotonated ligand leads to versatile results. This result corroborates with previous theoretical research on Hydrogen Atom Transfer in the reaction of metal-associated phenolic acids with $\mathrm{OH}^{\bullet}$ radical that showed that the ordering for antioxidant activity of the neutral phenolic acids does not change upon chelation with a divalent metal cation [45]. Our results also demonstrate that the solvation of complexes augments the antioxidant activity of the complexes. This augmentation is more sensitive for protic solvents (water and DMF). These results are consistent with previous studies on neutral ADPHT ligand [18] and other molecular systems $[47,48]$. The explanation is that the charge-separation process is quite sensible to polarity of solvent [49]. From Table 3, an increase of dipole of complexes is observed with the increase of the solvent's polarity declines the strength of $\mathrm{X}-\mathrm{H}$ $(\mathrm{X}=\mathrm{N}, \mathrm{C})$ bonds and subsequently increases the antioxidant activity of complexes formed. This conclusion is in line with previous works [47-51]. The survey of HOMO eigenvalues and dipole moments of optimized isolated ADPHT ligands (Table $4 \mathrm{~S}$ in the supporting information) compared to those of its complexes highlights the augmentation of antioxidant activity at the end of the complexation in various media.

Table 3 also shows an authentication of charge donation from ligand to metal atom. This donation is more sensitive for deprotonated ligands. Such a greater electron transfer from these ligands to metal (II) atom is a plausible explanation of their higher stabilities previously evoked. Our data also expose a greater electron transfer $\mathrm{Cu}$ (II)-complexes for both ligands. The calculated NBO charges on metal (II) atom are in good agreement with previous theoretical researches $[40,52]$ that disclosed the fact that greater electron transfer from the electron donor to the acceptor leads to higher stability. On the whole, the value of the metal charge carried by the metal cation in gas-phase was in the following ranges: $+(0.81-1.23)$ for iron, $+(0.95-1.04) e$ for nickel, $+(0.75-0.92) e$ for copper, and $+(0.9-1.61) e$ for zinc. This shows that a real charge transfer leads to an increase of the electronegativity 
TABLE 3: NBO charge (q/e) carried by the metal ion, the orbital frontier eigenvalues (eV), LUMO-HOMO gap ( $\Delta E$ in eV), and dipole moments (Debye) for ADPHT ligand-metal complexes in various media at B3LYP/Mixed I level.

\begin{tabular}{|c|c|c|c|c|c|c|c|c|c|c|c|}
\hline & $\mathrm{Q} / \mathrm{e}$ & $E_{\text {HOMO }}(\mathrm{eV})$ & $E_{\text {LUMO }}(\mathrm{eV})$ & $\Delta E(\mathrm{eV})$ & $\mu$ (Debye) & & $\mathrm{Q} / \mathrm{e}$ & $E_{\text {HOMO }}(\mathrm{eV})$ & $E_{\text {LUMO }}(\mathrm{eV})$ & $\Delta E(\mathrm{eV})$ & $\mu$ (Debye) \\
\hline \multicolumn{12}{|c|}{ Gas phase } \\
\hline la & 1.23 & -13.08 & -12.42 & 0.66 & 6.50 & $6 \mathrm{~A}$ & 1.06 & -9.23 & -8.04 & 1.19 & 8.09 \\
\hline $1 b$ & 1.22 & -13.02 & -12.27 & 0.75 & 6.41 & $6 B$ & 0.81 & -9.25 & -7.89 & 1.36 & 7.46 \\
\hline lc & 1.22 & -12.96 & -12.19 & 0.77 & 6.95 & $6 C$ & 1.05 & -9.23 & -7.85 & 1.38 & 7.60 \\
\hline $2 a$ & 1.05 & -13.60 & -12.70 & 0.90 & 1.79 & $7 \mathrm{~A}$ & 0.95 & -9.63 & -8.50 & 1.13 & 4.63 \\
\hline $2 b$ & 1.05 & -13.49 & -12.59 & 0.99 & 1.89 & $7 \mathrm{~B}$ & 0.95 & -9.58 & -8.41 & 1.17 & 4.51 \\
\hline $2 c$ & 1.04 & -13.49 & -12.50 & 0.99 & 2.52 & $7 \mathrm{C}$ & 0.95 & -9.57 & -8.40 & 1.17 & 4.92 \\
\hline $3 a$ & 0.92 & -13.76 & -12.85 & 0.91 & 7.87 & $8 \mathrm{~A}$ & 0.75 & -10.65 & -8.16 & 2.49 & 2.27 \\
\hline $3 b$ & 0.92 & -13.63 & -12.70 & 0.93 & 7.09 & $8 B$ & 0.85 & -9.78 & -8.41 & 1.37 & 2.71 \\
\hline $3 c$ & 0.92 & -13.59 & -12.63 & 0.96 & 6.93 & $8 C$ & 0.85 & -9.75 & -8.38 & 1.37 & 2.98 \\
\hline $5 a$ & 1.61 & -12.86 & -12.17 & 0.69 & 7.92 & $10 \mathrm{~A}$ & 1.50 & -9.05 & -8.15 & 0.9 & 9.57 \\
\hline $5 b$ & 1.62 & -12.80 & -12.04 & 0.76 & 7.98 & $10 \mathrm{~B}$ & 1.49 & -9.05 & -8.03 & 1.02 & 9.05 \\
\hline $5 c$ & 1.61 & -12.75 & -11.98 & 0.77 & 8.58 & $10 \mathrm{C}$ & 1.49 & -9.03 & -7.99 & 1.04 & 9.27 \\
\hline \multicolumn{12}{|c|}{ Water } \\
\hline 1a & 1.58 & -7.21 & -4.33 & 2.88 & 15.03 & $6 \mathrm{~A}$ & 1.41 & -6.68 & -3.39 & 3.29 & 15.17 \\
\hline $1 b$ & 1.57 & -7.20 & -4.28 & 2.92 & 14.85 & $6 B$ & 1.37 & -6.24 & -3.52 & 2.72 & 12.45 \\
\hline $1 c$ & 1.58 & -7.21 & -4.31 & 2.90 & 15.98 & $6 C$ & 0.90 & -7.21 & -4.31 & 2.9 & 15.98 \\
\hline $2 a$ & 1.36 & -7.28 & -5.40 & 1.88 & 1.36 & $7 \mathrm{~A}$ & 1.41 & -6.74 & -4.47 & 2.27 & 12.93 \\
\hline $2 b$ & 1.35 & -7.29 & -5.37 & 1.92 & 1.35 & $7 B$ & 1.37 & -6.73 & -4.42 & 2.31 & 12.14 \\
\hline $2 c$ & 1.35 & -7.30 & -5.38 & 1.92 & 1.35 & $7 \mathrm{C}$ & & -6.74 & -4.41 & 2.33 & 12.93 \\
\hline $3 a$ & 1.22 & -7.67 & -6.49 & 1.18 & 4.92 & $8 \mathrm{~A}$ & 1.25 & -7.18 & -4.73 & 2.45 & 3.64 \\
\hline $3 b$ & 1.24 & -7.48 & -6.46 & 1.02 & 7.11 & $8 B$ & 1.25 & -6.85 & --5.04 & 1.81 & 7.60 \\
\hline $3 c$ & 1.24 & -7.48 & -6.46 & 1.02 & 7.79 & $8 C$ & 1.25 & -6.84 & -5.03 & 1.81 & 7.80 \\
\hline $5 a$ & 1.61 & -7.09 & -2.22 & 4.87 & 17.97 & $10 \mathrm{~A}$ & 1.79 & -6.50 & -1.76 & 4.74 & 18.17 \\
\hline $5 b$ & 1.62 & -7.11 & -2.30 & 4.81 & 17.56 & $10 \mathrm{~B}$ & & & & & \\
\hline $5 c$ & 1.61 & -7.11 & -2.29 & 4.82 & 18.40 & $10 \mathrm{C}$ & 1.78 & 6.48 & 1.75 & 4.73 & 18.3 \\
\hline \multicolumn{12}{|c|}{ Benzene } \\
\hline la & 1.39 & -9.58 & -8.21 & 1.37 & 10.68 & $6 \mathrm{~A}$ & 1.10 & -7.71 & -5.63 & 2.08 & 10.03 \\
\hline $1 b$ & 1.49 & -9.59 & -8.10 & 1.49 & 10.24 & $6 B$ & & -7.70 & -5.64 & 2.06 & 10.7 \\
\hline lc & 1.51 & -9.60 & -8.09 & 1.51 & 10.95 & $6 C$ & 1.22 & -7.66 & -5.62 & 2.04 & 11.00 \\
\hline $2 a$ & 1.19 & -9.90 & -8.82 & 1.08 & 6.90 & $7 \mathrm{~A}$ & 1.09 & 7.84 & 6.45 & 1.39 & 8.57 \\
\hline $2 b$ & 1.18 & -9.87 & -8.75 & 1.12 & 6.70 & $7 B$ & & -7.82 & -6.37 & 2.04 & 8.29 \\
\hline $2 c$ & 1.18 & -9.83 & -8.73 & 1.10 & 7.45 & $7 \mathrm{C}$ & 1.08 & -7.82 & -6.36 & 1.46 & 8.77 \\
\hline $3 a$ & 0.97 & -10.37 & -9.23 & 1.14 & 6.43 & $8 \mathrm{~A}$ & 0.38 & -8.73 & -6.24 & 2.49 & 2.67 \\
\hline $3 b$ & 0.99 & -10.32 & -9.18 & 1.14 & 5.28 & $8 B$ & 0.42 & -7.97 & -6.52 & 1.45 & 5.51 \\
\hline $3 c$ & 0.99 & -10.29 & -9.16 & 1.13 & 5.74 & $8 C$ & 0.88 & -7.97 & -6.51 & 1.46 & 5.65 \\
\hline $5 a$ & & & & & & $10 \mathrm{~A}$ & 1.65 & -7.49 & -5.04 & 2.45 & 13.39 \\
\hline $5 b$ & 1.76 & -9.44 & -6.93 & 2.51 & 12.3 & $10 \mathrm{~B}$ & 1.64 & -7.50 & -4.97 & 2.53 & 12.79 \\
\hline $5 c$ & 1.75 & -9.44 & -6.97 & 2.47 & 13.4 & $10 \mathrm{C}$ & 1.76 & -7.50 & -5.00 & 2.50 & 13.21 \\
\hline \multicolumn{12}{|c|}{$D M F$} \\
\hline la & 1.57 & -7.28 & -4.48 & 2.80 & 14.83 & $6 \mathrm{~A}$ & - & - & - & - & - \\
\hline $1 b$ & 1.56 & -7.28 & -4.42 & 2.86 & 14.65 & $6 \mathrm{~B}$ & 1.40 & -6.68 & -3.45 & 3.23 & 14.10 \\
\hline $1 c$ & 1.55 & -7.28 & -4.39 & 2.89 & 16.04 & $6 C$ & 1.47 & -6.58 & -3.37 & 3.21 & 15.57 \\
\hline $2 a$ & 1.35 & -7.36 & -5.54 & 1.82 & 12.21 & $7 \mathrm{~A}$ & 1.24 & -6.77 & -4.55 & 2.22 & 12.78 \\
\hline $2 b$ & 1.34 & -7.37 & -5.50 & 1.87 & 12.02 & $7 B$ & 1.24 & -6.76 & -4.50 & 2.26 & 11.99 \\
\hline $2 c$ & 1.18 & -7.37 & -5.48 & 1.89 & 12.66 & $7 \mathrm{C}$ & 1.24 & -6.77 & -4.49 & 2.28 & 12.75 \\
\hline $3 a$ & 1.20 & -7.81 & -6.58 & 1.23 & 4.08 & $8 \mathrm{~A}$ & 0.80 & -7.23 & -4.77 & 2.46 & 3.60 \\
\hline $3 b$ & 1.22 & -7.61 & -6.55 & 1.06 & 6.28 & $8 B$ & 0.93 & -6.88 & -5.08 & 1.8 & 7.54 \\
\hline $3 c$ & 1.22 & -7.59 & -6.55 & 1.04 & 6.70 & $8 C$ & 0.92 & -6.88 & -5.08 & 1.8 & 7.73 \\
\hline $5 a$ & 1.85 & -7.16 & -2.46 & 4.70 & 17.77 & $10 \mathrm{~A}$ & 1.79 & -6.52 & -1.91 & 4.61 & 18.18 \\
\hline $5 b$ & 1.85 & -7.18 & -2.47 & 4.71 & 17.37 & $10 \mathrm{~B}$ & 1.85 & -7.18 & -2.47 & 4.71 & 17.37 \\
\hline $5 c$ & 1.85 & -7.18 & -2.45 & 4.73 & 18.23 & $10 \mathrm{C}$ & 1.78 & 6.52 & 1.88 & 4.64 & 18.11 \\
\hline
\end{tabular}




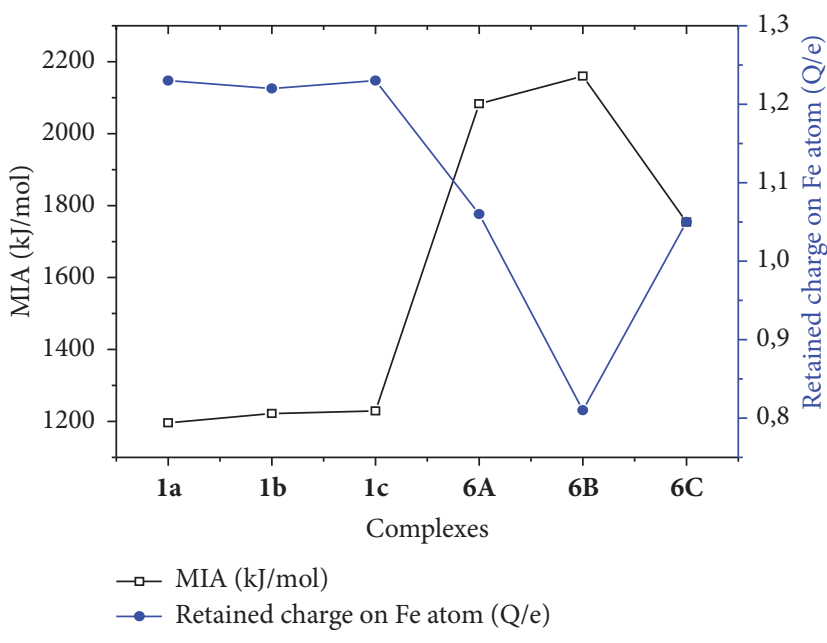

(a)

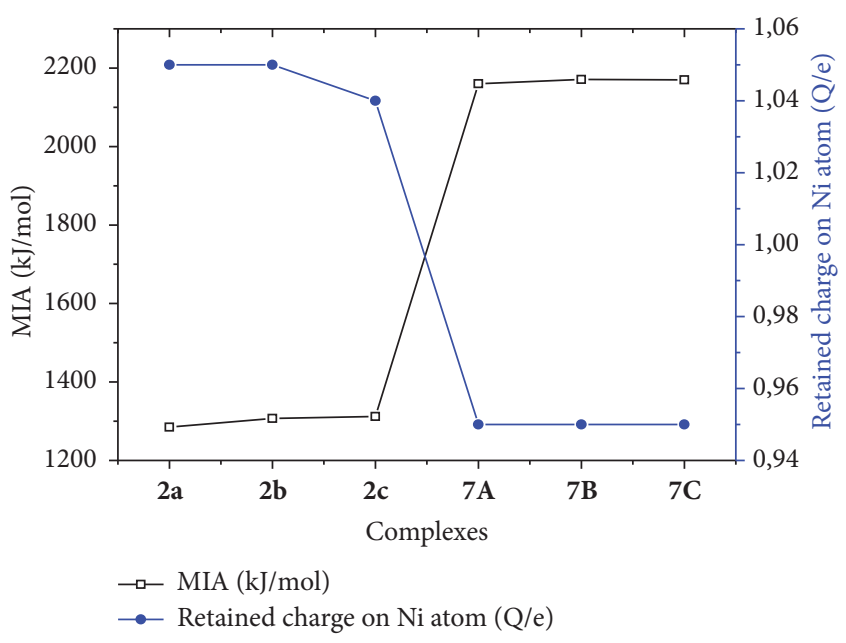

(b)

FIGURE 5: Correlation between the MIA (kJ/mol) and retained charge $(\mathrm{Q} / \mathrm{e})$ of Fe (a) and correlation between the MIA (kJ/mol) and retained charge $(\mathrm{Q} / \mathrm{e})$ of $\mathrm{Ni}(\mathrm{b})$.

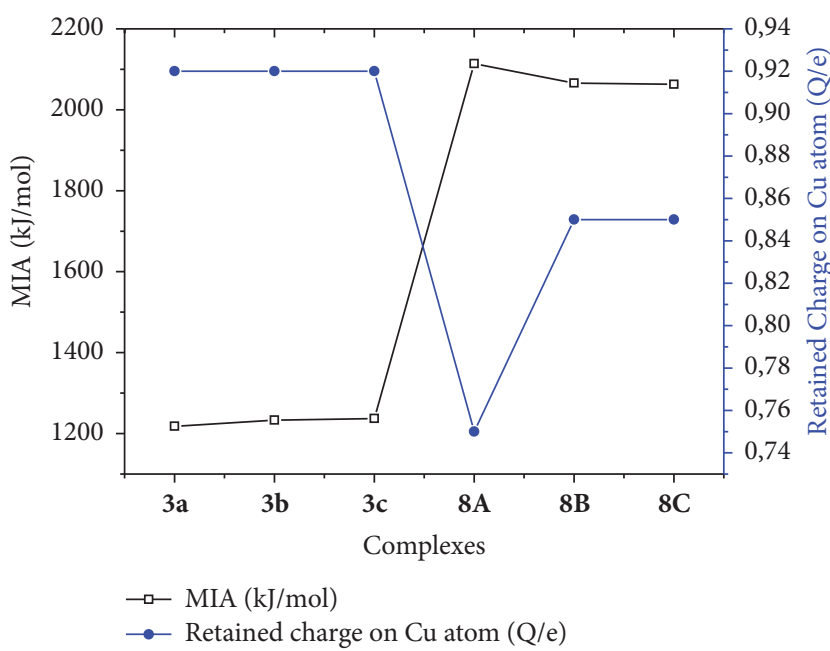

(a)

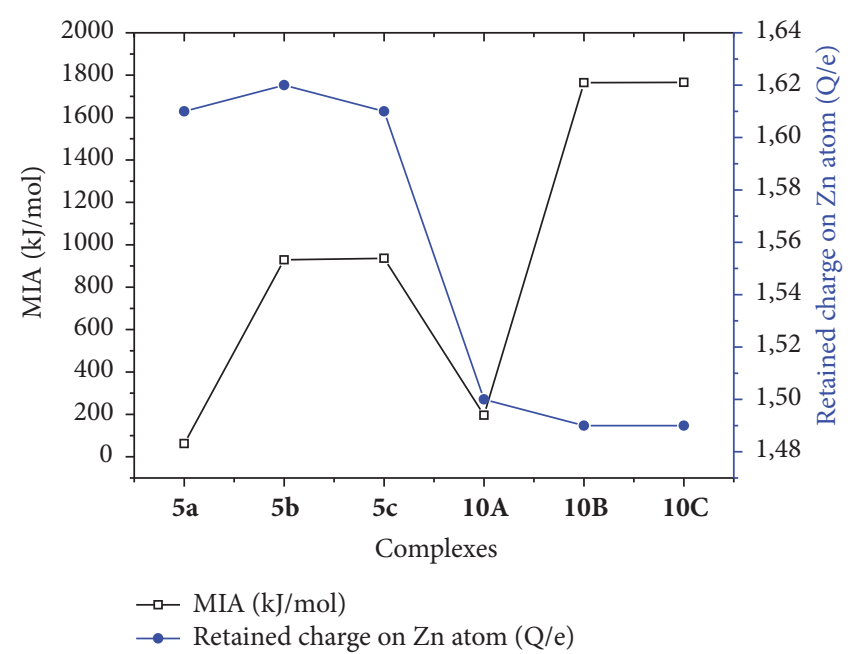

(b)

Figure 6: Correlation between the MIA (kJ/mol) and retained charge (Q/e) of Cu (a) and correlation between the MIA (kJ/mol) and retained charge (Q/e) of Zn.

of the metal ions that then has undergone a reduction. We then concluded that the metal cation plays an oxidation role towards both ligands. These observations are similar to those made on quercetin [53] and on phenolic acids [52].

To see the possible correlation between the retained NBO charge on the metal atom and metal MIA of each of the metal atoms, the two parameters are plotted (Figures 5 and 6). In the four cases $\left(\mathrm{Fe}^{2+}, \mathrm{Ni}^{2+}, \mathrm{Cu}^{2+}\right.$, and $\left.\mathrm{Zn}^{2+}\right)$, MIA values vary proportionately with the retained charge of the metal ion for deprotonated ADPHT ligands. On the contrary, MIA values vary inversely with the retained charge of the metal cation. Our results show that the solvation diminishes the electron donation from the ligand to metal atom, except for $5 i(i=\mathrm{a}$, $\mathrm{b}$, and c) complexes in water and for $8 \mathrm{C}$ in benzene.
The differences in retained charge on metal atom resulting from the various media were in the following ranges: $(0.15-0.46) e$ for water, $(0.05-0.43) e$ for benzene, and (0.14-0.59)e for DMF (see Table 3). Therefore, one could presume that the diminution of electron transfer is more enunciated in polar solvent.

So as to get detailed information on electron transfer in the coordination sphere complex, we presented in Figure 7 the second-order perturbation energy stabilization $\left(E_{2}\right)$ associated with the electron donation: electron donor $\left(\mathrm{O}_{2}\right.$ or $\left.\mathrm{O}_{3}\right)$ to the acceptor (metal atom). The $E_{2}$ values range from 4.4 to $49.68 \mathrm{~kJ} / \mathrm{mol}$ and from 2.76 to $119.98 \mathrm{~kJ} / \mathrm{mol}$, respectively, for metal-neutral ligand complexes and metal-deprotonated ligand complexes. The higher gap between the contribution 


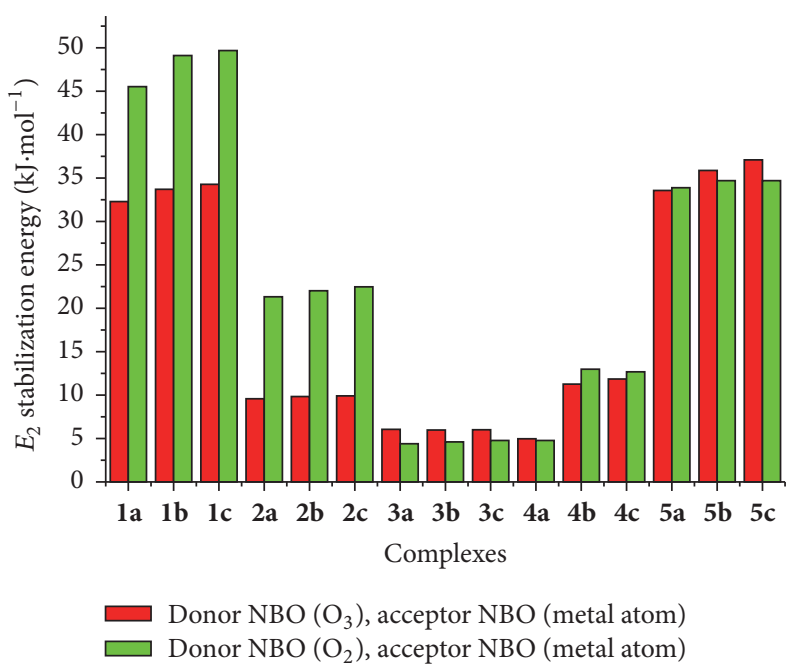

(a)

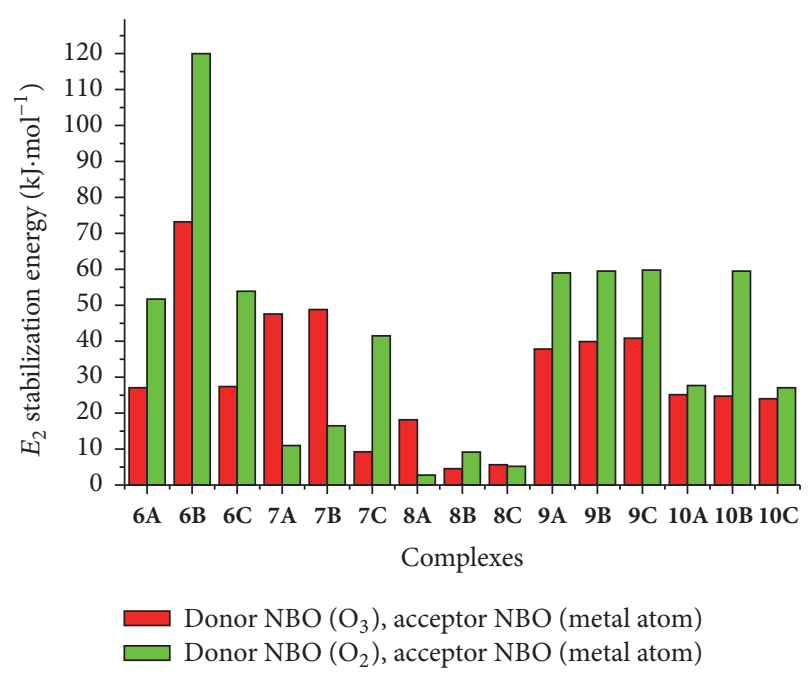

(b)

FIGURE 7: Second perturbative interaction energies $E_{2}\left(\mathrm{in} \mathrm{kJ} \cdot \mathrm{mol}^{-1}\right)$ between the first-row transition metals and lone pair electron ligand atoms (oxygen atom $\mathrm{O}_{3}$ and oxygen atom $\mathrm{O}_{2}$ ) for each complex: $E_{2}$ energies for neutral ligands (a) and $E_{2}$ energies for deprotonated ligands (b).

of $\mathrm{O}_{2} \rightarrow$ metal donation and that of $\mathrm{O}_{3} \rightarrow$ metal ones is obtained for $\mathrm{Fe}$-complexes in both cases (with exception to $6 \mathrm{C})$ in favor of the former one. This higher gap varies from 12.24 to $46.78 \mathrm{~kJ} / \mathrm{mol}$. This higher contribution of $\mathrm{O}_{2} \rightarrow$ metal donation is also observed when the $\mathrm{Cu}^{+}$and $\mathrm{Zn}^{2+}$ were chelated to the deprotonated ligands. Figure 6 also exhibits a drastic drop of both contributions for $\mathrm{Cu}^{2+}$-complexes. The negligible contribution of $\mathrm{O}_{2} \rightarrow$ metal donation $(2,76 \mathrm{~kJ} / \mathrm{mol})$ highlighted the monodental nature of $8 \mathrm{~A}$ structure evoked in the prior geometrical analysis. To better appreciate the impact of the metal chelation beyond the coordination innersphere, we made a comparison between calculated energies of hyperconjugative interaction for neutral ADPHT ligands and those of its complexes (Table $5 \mathrm{~S}$ in supporting information). In the whole, this comparison exhibits the noteworthy influence of the metal chelation on the interaction within both ligands used in this work. This fact is in agreement with the significant activation of adjacent bonds of metal cations previously underlined.

The topological parameters obtained at B3LYP/Mixed II level are inserted in Tables 4 and 5 . The positive $\nabla^{2}(\rho(r))$ values and negative $H(r)$ values obtained illustrate that the $\mathrm{M}^{2+}-\mathrm{O}_{i}(i=2,3)$ bonds are partly covalent. This result is confirmed by the fact $0.5<-G(r) / \nu(r)<1$. Close inspection of Table 4 reveals that the $\rho(r)$ values of $\mathrm{M}^{2+}-\mathrm{O}_{3}$ bond are larger than that for $\mathrm{M}^{2+}-\mathrm{O}_{2}$ bond for $\mathrm{M}^{2+}$-neutral ADPHT complexes with exception of 2a. This observation points out that $\mathrm{M}^{2+}-\mathrm{O}_{3}$ bonds are stronger than $\mathrm{M}^{2+}-\mathrm{O}_{2}$ bond of these complexes. This corroborates the fact that $\mathrm{M}^{2+}$ $\mathrm{O}_{2}$ bonds are stronger than $\mathrm{M}^{2+}-\mathrm{O}_{2}$ bonds. Nevertheless, Table $4 \mathrm{~S}$ displays contrary information for $\mathrm{M}^{2+}$-deprotonated ADPHT complexes. The $\rho(r)$ values of $\mathrm{M}^{2+}-\mathrm{O}_{i}(i=2,3)$ in $\mathrm{Cu}^{2+}$-deprotonated ADPHT complexes are higher than that for $\mathrm{Cu}^{+}$complexes. This confirms the preference of $\mathrm{Cu}^{2+}$ to bind deprotonated ligand. The $\rho(r)$ values of $\mathrm{M}^{2+}-\mathrm{O}_{i}(i=$ $2,3)$ in $\mathrm{M}^{2+}$-deprotonated ADPHT complexes are sensitively higher than its homolog in $\mathrm{M}^{2+}$-neutral ADPHT complexes with exception to $\mathrm{Fe}^{2+}$-complexes. The $\rho(r)$ value difference ranges from 0.006 to 0.038 . Consequently, the $\mathrm{M}^{2+}-\mathrm{O}_{i}(i=$ $2,3)$ in $\mathrm{M}^{2+}$-deprotonated ADPHT complexes are stronger than that in $\mathrm{M}^{2+}$-neutral ADPHT complexes. This result is in line with the fact that metal ligand distances in the former are lower.

3.4. Proton Affinity. In order to investigate the possibility of deprotonation of metal-neutral ligand complexes in various media, the authors analyzed the PA and PAFE values of the complexes. We absolutely need the enthalpy and free energy of $\mathrm{H}^{+}$to determine the thermodynamic energies. The calculated values of these thermodynamic energies used in this work are compiled in Table 6S. In the interest of comparison, we presented in Table 7S the PA and PAFE values of isolated neutral ligands and its complexes in various media. A major drop of the PA values is observed when passing from ligands to complexes in gas-phase. This drop is lower for $\mathrm{Cu}^{+}$complexes.

Such a drop discloses the notable enhancement of antioxidant activities of neutral ligands in gas-phase. This fact is in good agreement with the increase of the $\mathrm{X}-\mathrm{H}$ bond distances induced by the metal chelation (shown in Figure 1S). This augmentation of the antioxidant activities has been pointed out in our previous researches [54]. The difference in PA values from ligands to complexes declines in solution-phase.

We therefore concluded that the solvation reduces the enhancement of the antioxidant activities induced by the metal chelation. The positive PA values obtained for all the complexes revealed that the deprotonation of metalneutral ligand complexes is endothermic in gas-phase, water, 
TABLE 4: Topological parameters of the metal-ligand for optimized structures at B3LYP/Mixed II level for neutral ADPHT-M ${ }^{2+}$-complexes.

\begin{tabular}{|c|c|c|c|c|c|c|c|c|c|c|}
\hline & \multicolumn{5}{|c|}{$\mathrm{M}^{2+}-\mathrm{O}_{2}$} & \multicolumn{5}{|c|}{$\mathrm{M}^{2+}-\mathrm{O}_{3}$} \\
\hline & 1a & $2 a$ & $3 a$ & $4 a$ & $5 a$ & la & $2 a$ & $3 \mathbf{a}$ & $4 a$ & $5 a$ \\
\hline$\rho(r)$ & 0.121 & 0.133 & 0.108 & 0.107 & 0.112 & 0.134 & 0.133 & 0.113 & 0.106 & 0.113 \\
\hline$\nabla^{2}(\rho(r))$ & 0.852 & 0.902 & 0.564 & 0.550 & 0.510 & 0.852 & 0.878 & 0.589 & 0.526 & 0.510 \\
\hline$H(r)$ & -0.009 & -0.022 & -0.036 & -0.038 & -0.047 & -0.018 & -0.022 & -0.037 & -0.039 & -0.048 \\
\hline$G(r)$ & 0.222 & 0.247 & 0.176 & 0.175 & 0.175 & 0.230 & 0.247 & 0.176 & 0.170 & 0.176 \\
\hline$\nu(r)$ & -0.231 & -0.269 & -0.212 & -0.213 & -0.222 & -0.248 & -0.269 & -0.212 & -0.209 & -0.224 \\
\hline \multirow[t]{2}{*}{$-G(r) / \nu(r)$} & 0.962 & 0.920 & 0.833 & 0.823 & 0.787 & 0.929 & 0.920 & 0.833 & 0.815 & 0.785 \\
\hline & $1 b$ & $2 \mathbf{b}$ & $3 b$ & $4 \mathrm{~b}$ & $5 b$ & $\mathbf{l b}$ & $2 b$ & $3 \mathbf{b}$ & $4 b$ & $5 b$ \\
\hline$\rho(r)$ & 0.124 & 0.133 & 0.109 & 0.108 & 0.113 & 0.133 & 0.135 & 0.115 & 0.106 & 0.115 \\
\hline$\nabla^{2}(\rho(r))$ & 0.846 & 0.908 & 0.572 & 0.552 & 0.516 & 0.856 & 0.888 & 0.600 & 0.527 & 0.521 \\
\hline$H(r)$ & -0.011 & -0.022 & -0.036 & -0.038 & -0.048 & -0.017 & -0.023 & -0.037 & -0.039 & -0.049 \\
\hline$G(r)$ & 0.223 & 0.249 & 0.179 & 0.176 & 0.177 & 0.231 & 0.245 & 0.187 & 0.170 & 0.229 \\
\hline$\nu(r)$ & -0.234 & -0.270 & -0.214 & -0.213 & -0.225 & -0.248 & -0.269 & -0.225 & -0.209 & -0.229 \\
\hline \multirow[t]{2}{*}{$-G(r) / \nu(r)$} & 0.953 & 0.920 & 0.834 & 0.823 & 0.787 & 0.931 & 0.913 & 0.834 & 0.815 & 0.785 \\
\hline & $1 c$ & $2 c$ & $3 c$ & $4 \mathrm{c}$ & $5 c$ & $1 c$ & $2 c$ & $3 c$ & $4 c$ & $5 c$ \\
\hline$\rho(r)$ & 0.122 & 1.34 & 0.110 & 0.108 & 0.113 & 0.137 & 0.136 & 0.116 & 0.107 & 0.115 \\
\hline$\nabla^{2}(\rho(r))$ & 0.856 & 0.911 & 0.576 & 0.552 & 0.517 & 0.877 & 0.890 & 0.602 & 0.528 & 0.522 \\
\hline$H(r)$ & -0.009 & -0.022 & -0.036 & -0.038 & -0.048 & -0.019 & -0.024 & -0.038 & -0.039 & -0.049 \\
\hline$G(r)$ & 0.223 & 0.250 & 0.180 & 0.176 & 0.177 & 0.238 & 0.246 & 0.188 & 0.171 & 0.180 \\
\hline$\nu(r)$ & -0.233 & -0.271 & -0.215 & -0.213 & -0.225 & -0.257 & -0.270 & -0.226 & -0.209 & -0.230 \\
\hline$-G(r) / \nu(r)$ & 0.959 & 0.920 & 0.834 & 0.823 & 0.787 & 0.926 & 0.912 & 0.834 & 0.815 & 0.785 \\
\hline
\end{tabular}

TABLE 5: Topological parameters of the metal-ligand for optimized structures at B3LYP/Mixed II level for deprotonated ADPHT-M ${ }^{2+}$. complexes.

\begin{tabular}{|c|c|c|c|c|c|c|c|c|}
\hline & \multicolumn{4}{|c|}{$\mathrm{M}^{2+}-\mathrm{O}_{2}$} & \multicolumn{4}{|c|}{$\mathrm{M}^{2+}-\mathrm{O}_{3}$} \\
\hline & $6 \mathrm{~A}$ & $7 \mathrm{~A}$ & $8 \mathrm{~A}$ & 9A & $6 \mathrm{~A}$ & $7 \mathrm{~A}$ & $8 \mathrm{~A}$ & $9 A$ \\
\hline$\rho(r)$ & 0.162 & 0.158 & 0.138 & 0.132 & 0.131 & 0.139 & 0.125 & 0.120 \\
\hline$\nabla^{2}(\rho(r))$ & 1.019 & 1.004 & 0.759 & 0.634 & 0.865 & 0.935 & 0.679 & 0.552 \\
\hline$H(r)$ & -0.035 & -0.036 & -0.045 & -0.058 & -0.015 & -0.024 & -0.039 & -0.052 \\
\hline$G(r)$ & 0.290 & 0.287 & 0.235 & 0.216 & 0.232 & 0.258 & 0.210 & 0.190 \\
\hline$\nu(r)$ & -0.325 & -0.322 & -0.281 & -0.274 & -0.247 & -0.282 & -0.248 & -0.242 \\
\hline \multirow[t]{2}{*}{$-G(r) / \nu(r)$} & 0.893 & 0.889 & 0.838 & 0.790 & 0.937 & 0.914 & 0.842 & 0.784 \\
\hline & $6 B$ & $7 B$ & $8 B$ & $9 B$ & $6 \mathrm{~B}$ & $7 B$ & $8 B$ & 9B \\
\hline$\rho(r)$ & 0.162 & 0.158 & 0.138 & 0.132 & 0.133 & 0.140 & 0.126 & 0.121 \\
\hline$\nabla^{2}(\rho(r))$ & 1.017 & 1.003 & 0.762 & 0.633 & 0.869 & 0.932 & 0.684 & 0.556 \\
\hline$H(r)$ & -0.035 & -0.036 & -0.046 & -0.058 & -0.016 & -0.025 & -0.040 & -0.053 \\
\hline$G(r)$ & 0.289 & 0.286 & 0.236 & 0.216 & 0.234 & 0.258 & 0.211 & 0.191 \\
\hline$\nu(r)$ & -0.324 & -0.322 & -0.282 & -0.274 & -0.250 & -0.283 & -0.251 & -0.244 \\
\hline \multirow[t]{2}{*}{$-G(r) / \nu(r)$} & 0.892 & 0.889 & 0.838 & 0.789 & 0.934 & 0.911 & 0.841 & 0.784 \\
\hline & $6 \mathrm{C}$ & $7 \mathrm{C}$ & $8 C$ & $9 \mathrm{C}$ & $6 \mathrm{C}$ & $7 \mathrm{C}$ & $8 C$ & $9 \mathrm{C}$ \\
\hline$\rho(r)$ & 0.162 & 0.158 & 0.138 & 0.132 & 0.133 & 0.141 & 0.126 & 0.121 \\
\hline$\nabla^{2}(\rho(r))$ & 1.017 & 1.005 & 0.758 & 0.634 & 0.870 & 0.933 & 0682 & 0.554 \\
\hline$H(r)$ & -0.035 & -0.036 & -0.046 & -0.058 & -0.017 & -0.025 & -0.040 & -0.053 \\
\hline$G(r)$ & 0.289 & 0.287 & 0.235 & 0.216 & 0.234 & 0.259 & 0.210 & 0.191 \\
\hline$\nu(r)$ & -0.324 & -0.323 & -0.281 & -0.274 & -0.251 & -0.284 & -0.250 & -0.244 \\
\hline$-G(r) / \nu(r)$ & 0.892 & 0.889 & 0.837 & 0.789 & 0.933 & 0.911 & 0.840 & 0.784 \\
\hline
\end{tabular}


and DMF (3a complex excepted). It is fair to note that this deprotonation remains endothermic in benzene only for $\mathrm{Cu}^{+}$and $\mathrm{Zn}^{2+}$-complexes. The positive PAFE values obtained show that the deprotonation of metal-neutral ligand complexes is not spontaneous with exception made to minority of endothermic deprotonation previously mentioned.

\section{Conclusions}

In this study, we have presented the B3LYP/Mixed I and B3LYP/Mixed II calculations which allowed us to treat the complexation of 3-alkyl-4-phenylacettylamino-4,5-dihydro1h-1,2,4-triazol-5-one derivatives by metal cation $\left(\mathrm{Fe}^{2+}, \mathrm{Ni}^{2+}\right.$, $\mathrm{Cu}^{2+}, \mathrm{Cu}^{+}$, and $\left.\mathrm{Zn}^{2+}\right)$. The optimizations yield a unique coordination mode $\left(\mathrm{O}_{3}, \mathrm{O}_{2}\right)$ independent of the nature of the ligand. In the whole, the optimization leads to longer $\mathrm{M}-\mathrm{O}_{2}$

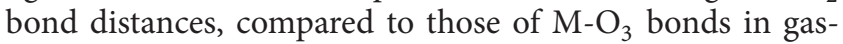
phase. Our results indicate that the $\mathrm{M}^{2+}-\mathrm{O}_{i}(i=2,3)$ bond distances yielded by B3LYP/ Mixed II are shorter than those relative to B3LYP/Mixed I due to the poor description of the electron-electron repulsion by this latter. The variations of the B3LYP/Mixed I geometrical parameters are very variable in solution-phase. The metal chelation slightly induces an increase of the X-H bond distances that leads to the enhancement of the antioxidant activities of ligands. This shortening of the $\mathrm{X}-\mathrm{H}$ bond is in agreement with the major drop of the PA values observed when passing from ligands to complexes in gas-phase. The highly negative values of the complexation energies of the M-ADPHT complexes in various media showed that the metal chelation is exothermic. The authors' data revealed that the solvation of complexes drops these complexation energies. This diminution is more pronounced for protic solvents. The highest affinity is obtained for $\mathrm{Ni}^{2+}$. From our calculations, we conclude that the formation of $\mathrm{M}^{n+}$-ADPHT complexes $(n=1,2)$ is spontaneous. The HOMO-LUMO gap values reveal that deprotonated ADPHT ligand- $\mathrm{M}^{2+}$-complexes are the most stable ones in gas-phase. The highest value of the HOMO-LUMO gap is obtained for the monodental $\mathrm{Cu}^{2+}$ complexes obtained. The variation of the values of this gap revealed the fact that the solvation enhances the stability of the complexes. This enhancement is more pronounced in protic solvents. For the neutral ligands, the metal chelation does not affect the increasing order of the HOMO values (with exception made to $\mathrm{Ni}^{2+}$ ) in gasphase. Our results also show that the solvation of complexes augments the HOMO values and therefore enhances the antioxidant activity of the complexes. The calculated NBO charge on metal (II) atom illustrates a clear relationship between greater electron transfer from the electron donor to the acceptor and higher stability. The metal cation then plays an oxidation role towards both ligands. The MIA value varies proportionately with the retained charge of the metal ion for deprotonated ADPHT ligands. The comparison of calculated energies of hyperconjugative interaction for neutral ADPHT ligands and those of its complexes exhibits the noteworthy influence of the metal chelation on the interaction within both ligands used. The topological parameters yielded from
Quantum Theory of Atom in Molecules (QTAIM) indicate that metal-ligand bonds are partly covalent.

\section{Conflicts of Interest}

The authors declare that there are no conflicts of interest regarding the publication of this paper.

\section{Acknowledgments}

The authors are grateful to Bénoît Champagne (Université Catholique de Louvain (UCL), Belgium) for his support. This work has been supported by the Ministry of Higher Education of Cameroon.

\section{References}

[1] I. Dalle-Donne, R. Rossi, D. Giustarini, A. Milzani, and R. Colombo, "Protein carbonyl groups as biomarkers of oxidative stress," Clinica Chimica Acta, vol. 329, no. 1-2, pp. 23-38, 2003.

[2] J. K. Andersen, "Oxidative stress in neurodegeneration: cause or consequence?” Nature Medicine, vol. 10, pp. S18-S25, 2004.

[3] E. Esposito, D. Ratilio, V. Di Glulia, M. Cacchio, and S. Algeri, "A review of specific dietary antioxidants and the ... for novel therapeutic approach," Progress in Neurobiology, vol. 23, p. 719, 2002.

[4] C. Behl, "Alzheimer's disease and oxidative stress: Implications for novel therapeutic approaches," Progress in Neurobiology, vol. 57, no. 3, pp. 301-323, 1999.

[5] M. Senevirathne, S.-H. Kim, N. Siriwardhana, J.-H. Ha, K.-W. Lee, and Y.-J. Jeon, "Antioxidant potential ofecklonia cavaon reactive oxygen species scavenging, metal chelating, reducing power and lipid peroxidation inhibition," Food Science and Technology International, vol. 12, no. 1, pp. 27-38, 2006.

[6] A. Michalak, "Phenolic compounds and their antioxidant activity in plants growing under heavy metal stress," Polish Journal of Environmental Studies, vol. 15, no. 4, pp. 523-530, 2006.

[7] T. P. A. Devasagayam and J. P. Kamat, "Biological significance of singlet oxygen," Indian Journal of Experimental Biology, vol. 40, no. 11, pp. 680-692, 2002.

[8] S. Cuzzocrea, D. P. Riley, A. P. Caputi, and D. Salvemini, "Antioxidant therapy: a new pharmacological approach in shock, inflammation, and ischemia/reperfusion injury," Pharmacological Reviews, vol. 53, no. 1, pp. 135-159, 2001.

[9] Y. Gilgun-Sherki, Z. Rosenbaum, E. Melamed, and D. Offen, "Antioxidant therapy in acute central nervous system injury: Current state," Pharmacological Reviews, vol. 54, no. 2, pp. 271284, 2002.

[10] W. W. Hope, E. M. Billaud, J. Lestner, and D. W. Denning, "Therapeutic drug monitoring for triazoles," Current Opinion in Infectious Diseases, vol. 21, no. 6, pp. 580-586, 2008.

[11] G. R. Kokil, P. V. Rewatkar, S. Gosain et al., "Synthesis and in vitro evaluation of novel 1, 2, 4-triazole derivatives as antifungal agents," Letters in Drug Design and Discovery, vol. 7, no. 1, pp. 46-49, 2010.

[12] N. Upmanyu, S. Kumar, M. D. Kharya, K. Shah, and P. Mishra, "Synthesis and anti-microbial evaluation of some novel 1,2,4 -triazole derivatives," Acta Poloniae Pharmaceutica - Drug Research, vol. 68, no. 2, pp. 213-221, 2011. 
[13] O. D. Cretu, S. F. Barbuceanu, G. Saramet, and C. Draghici, "Synthesis and characterization of some 1,2,4-triazole-3-thiones obtained from intramolecular cyclization of new 1-(4-(4-Xphenylsulfonyl)benzoyl)-4-(4- iodophenyl)-3-thiosemicarbazides," Journal of the Serbian Chemical Society, vol. 75, no. 11, pp. 1463-1471, 2010.

[14] S. Hussain, J. Sharma, and M. Amir, "Synthesis and antimicrobial activities of 1,2,4-triazole and 1,3,4-thiadiazole derivatives of 5-amino-2-hydroxybenzoic acid," E-Journal of Chemistry, vol. 5, no. 4, pp. 963-968, 2008.

[15] L. P. Guan, Q. H. Jin, G. R. Tian, K. Y. Chai, and Z. S. Quan, "Synthesis of some quinoline-2(1H)-one and 1, 2, 4 - triazolo [4, 3 -a] quinoline derivatives as potent anticonvulsants," Journal of Pharmacy and Pharmaceutical Sciences, vol. 10, no. 3, pp. 254262, 2007.

[16] M. Oyaizu, "Studies on products of the browning reaction," Japanese Journal of Nutrition, vol. 44, no. 6, pp. 307-315, 1986.

[17] M. S. Blois, "Antioxidant determinations by the use of a stable free radical," Nature, vol. 181, no. 4617, pp. 1199-1200, 1958.

[18] J. H. Nono, D. M. Bikélé, J. N. Ghogomu et al., "DFT-study on antioxydant of 3-alkyl-4-phenylacetylamino-1h-1,2,4-triazol-5ones and its derivatives," Journal of Chemistry and Chemical Engineering, vol. 8, pp. 1109-1124, 2014.

[19] M. Leopoldini, N. Russo, S. Chiodo, and M. Toscano, "Iron chelation by the powerful antioxidant flavonoid quercetin," Journal of Agricultural and Food Chemistry, vol. 54, no. 17, pp. 6343-6351, 2006.

[20] M. J. Frisch, G. W. Trucks, H. B. Schlegel et al., Gaussian 03, Revision A.1, Gaussian, Inc., Pittsburgh, Pa, USA, 2003.

[21] C. Lee, W. Yang, and R. G. Parr, "Development of the ColleSalvetti correlation-energy formula into a functional of the electron density," Physical Review B, vol. 37, no. 2, pp. 785-789, 1988.

[22] P. J. Hay and W. R. Wadt, “Ab initio effective core potentials for molecular calculations. Potentials for the transition metal atoms Sc to Hg," The Journal of Chemical Physics, vol. 82, no. 1, pp. 270283, 1985.

[23] J. Sabolović, C. S. Tautermann, T. Loerting, and K. R. Liedl, "Modeling anhydrous and aqua copper(II) amino acid complexes: a new molecular mechanics force field parametrization based on quantum chemical studies and experimental crystal data," Inorganic Chemistry, vol. 42, no. 7, pp. 2268-2279, 2003.

[24] T. J. M. De Bruin, A. T. M. Marcelis, H. Zuilhof, and E. J. R. Sudhölter, "Geometry and electronic structure of bis(glycinato)- $\mathrm{Cu}(\mathrm{II}) \cdot 2 \mathrm{H}_{2} \mathrm{O}$ complexes as studied by density functional B3LYP computations," Physical Chemistry Chemical Physics, vol. 1, no. 18, pp. 4157-4163, 1999.

[25] E. Cances and B. Mennucci, "New applications of integral equations methods for solvation continuum models: ionic solutions and liquid crystals," Journal of Mathematical Chemistry, vol. 23, no. 3-4, pp. 309-326, 1998.

[26] E. Cances, B. Mennucci, and J. Tomasi, "A new integral equation formalism for the polarizable continuum model: theoretical background and applications to Isotropic and anisotropic dielectrics," The Journal of Chemical Physics, vol. 107, pp. 30323041, 1997.

[27] L. Rodrìguez-Santiago, M. Sodupe, and J. Tortajada, "The different nature of bonding in $\mathrm{Cu}^{+}$-glycine and $\mathrm{Cu}^{2+}$-glycine," The Journal of Physical Chemistry B, vol. 103, pp. 2310-2317, 1999.

[28] T. Shoeib, C. F. Rodriquez, K. W. M. Siu, and A. C. Hopkinson, "A comparison of copper(I) and silver(I) complexes of glycine, diglycine and triglycine," Physical Chemistry Chemical Physics, vol. 3, no. 5, pp. 853-861, 2001.

[29] M. S. F. Jahromi and A. Fattahi, "DFT study of the interaction of thymine with $\mathrm{Cu}^{+}$and $\mathrm{Zn}^{2+}$," Transactions C: Chemistry and Chemical Engineering, vol. 16, no. 2, pp. 75-80, 2009.

[30] R. Parajuli, "DFT study of $\mathrm{Cu}^{+}$-thymine and $\mathrm{Zn}^{2+}$-thymine complexes in the gas phase: HOMO-LUMO approach," Acta Chimica and Pharmaceutica Indica, vol. 2, no. 2, pp. 85-94, 2012.

[31] R. P. Gangadharana and S. S. Krishnanb, "Natural Bond Orbital (NBO) population analysis of 1-azanapthalene-8-ol," Acta Physica Polonica A, vol. 125, no. 1, pp. 18-22, 2014.

[32] R. F. W. Bader, Atoms in Molecules-A Quantum Theory, Oxford University Press, Oxford, UK, 1990.

[33] L. Tian and C. Fei-Wu, "Calculation of molecular orbital composition," Acta Chimica Sinica, vol. 69, no. 20, pp. $2393-$ 2406, 2011.

[34] G. V. Baryshnikov, B. F. Minaev, V. A. Minaeva, A. T. Podgornaya, and H. Ågren, "Application of Bader's atoms in molecules theory to the description of coordination bonds in the complex compounds of $\mathrm{Ca}^{2+}$ and $\mathrm{Mg}^{2+}$ with methylidene rhodanine and its anion," Russian Journal of General Chemistry, vol. 82, no. 7, pp. 1254-1262, 2012.

[35] E. Constantino, L. Rodríguez-Santiago, M. Sodupe, and J. Tortajada, "Interaction of $\mathrm{Co}+$ and $\mathrm{Co} 2+$ with glycine. A theoretical study," Journal of Physical Chemistry A, vol. 109, no. 1, pp. 224-230, 2005.

[36] M. Rosi and C. W. Bauschlicher Jr., "The binding energies of one and two water molecules to the first transition-row metal positive ions," The Journal of Chemical Physics, vol. 90, no. 12, pp. 7264-7272, 1989.

[37] M. Rosi and C. W. Bauschlicher Jr., "The binding energies of one and two water molecules to the first transitionrow metal positive ions. II," The Journal of Chemical Physics, vol. 92, no. 3, pp. 1876-1878, 1990.

[38] E. Magnusson and N. W. Moriarty, "Binding Patterns in SingleLigand Complexes of NH3, H2, OH-, and F- with First Series Transition Metals," Inorganic Chemistry, vol. 35, no. 19, pp. 5711$5719,1996$.

[39] D. Walter and P. B. Armentrout, "Sequential bond dissociation energies of $\mathrm{M}+(\mathrm{NH} 3)(\mathrm{x})(\mathrm{x}=1-4)$ for $\mathrm{M}=\mathrm{Ti}-\mathrm{Cu}$," Journal of the American Chemical Society, vol. 120, no. 13, pp. 3176-3187, 1998.

[40] M. Remko and B. M. Rode, "Catalyzed peptide bond formation in the gas phase," Physical Chemistry Chemical Physics, vol. 3, no. 21, pp. 4667-4673, 2001.

[41] F. C. A. Lima, R. B. Viana, J. W. M. Carneiro, M. Comar Jr., and A. B. F. Da Silva, "Coordination ability of polyether and polyamine ligands: A density functional theory study of firstand second-row transition metals," Journal of Computational and Theoretical Nanoscience, vol. 10, no. 9, pp. 2034-2040, 2013.

[42] F. Boukli-Hacene, S. Ghalem, M. Merad, and W. Soufi, “Theoretical study of interaction of some heavy metals with carbohydrates in aqueous solution," Asian Journal of Chemistry, vol. 28, no. 6, pp. 1293-1296, 2016.

[43] F. Lamchouri, H. Toufi, S. M. Bouzzine, M. Hamidi, and M. Bouachrine, "Experimental and computational study of biological activities of alkaloids isolated from Peganum harmala seeds," Journal of Materials and Environmental Science, vol. 1, pp. 343-352, 2010.

[44] S. Singh, J. Singh, S. Gulia, and R. Kakkar, "Metal ion selectivity of Kojate complexes: theoretical study," Journal of Theoretical Chemistry, pp. 1-9, 2013. 
[45] M. Nsangou, J. J. Fifen, Z. Dhaouadi, and S. Lahmar, "Hydrogen atom transfer in the reaction of hydroxycinnamic acids with radical ${ }^{\circ} \mathrm{OH}$ and radical ${ }^{\circ} \mathrm{HO}_{2}$ radicals: DFT study," Journal of Molecular Structure, vol. 862, no. 1-3, pp. 53-59, 2008.

[46] E. G. Bakalbassis, A. Chatzopoulou, V. S. Melissas, M. Tsimidou, M. Tsolaki, and A. Vafiadis, " $A b$ initio and density functional theory studies for the explanation of the antioxidant activity of certain phenolic acids," Lipids, vol. 36, no. 2, pp. 181-190, 2001.

[47] M. Najafi, "On the antioxidant activity of the ortho and meta substituted daidzein derivatives in the gas phase and solvent environment," Journal of the Mexican Chemical Society, vol. 58, no. 1, pp. 36-45, 2014.

[48] O. Holtomo, M. Nsangou, J. J. Fifen, and O. Motapon, "Antioxidative potency and UV-Vis spectra features of the compounds resulting from the chelation of $\mathrm{Fe}^{2+}$ by caffeic acid phenethyl ester and two of its derivatives," Computational and Theoretical Chemistry, vol. 1067, pp. 135-147, 2015.

[49] J. Rimarčík, V. Lukeš, E. Klein, and M. Ilčin, "Study of the solvent effect on the enthalpies of homolytic and heterolytic nh bond cleavage in p-phenylenediamine and tetracyano-pphenylenediamine," Journal of Molecular Structure, vol. 952, no. 1-3, pp. 25-30, 2010.

[50] O. Holtomo, M. Nsangou, J. J. Fifen, and O. Motapon, "DFT study of the effect of solvent on the $\mathrm{H}$-atom transfer involved in the scavenging of the free radicals ${ }^{\circ} \mathrm{HO}_{2}$ and ${ }^{\circ} \mathrm{O}_{2}{ }^{-}$by caffeic acid phenethyl ester and some of its derivatives," Journal of Molecular Modeling, vol. 20, no. 11, pp. 1-13, 2014.

[51] J. J. Fifen, M. Nsangou, Z. Dhaouadi, O. Motapon, and N. Jaidane, "Solvent effects on the antioxidant activity of 3,4dihydroxyphenylpyruvic acid: DFT and TD-DFT studies," Computational and Theoretical Chemistry, vol. 966, no. 1-3, pp. 232-243, 2011.

[52] J. J. Fifen, M. Nsangou, Z. Dhaouadi, O. Motapon, and S. Lahmar, "Single or double hydrogen atom transfer in the reaction of metal—associated phenolic acids with ${ }^{\circ} \mathrm{OH}$ radical: DFT Study," Journal of Molecular Structure: THEOCHEM, vol. 901, no. 1-3, pp. 49-55, 2009.

[53] S. Fioruci, Acquisition et analyse des données pour l'expérience de recherche de matière noire (EDELWEISS) [M.S. thesis], Université de Nice-Sophia Antipolis, 2006.

[54] D. M. Bikélé, J. M. Zobo, D. Lissouck, E. Younang, J. H. Nono, and L. M. Mbaze, "DFT investigation of chelation of divalent cations by some 4-benzylidenamino-4, 5-dihydro-1h-1, 2, 4triazol-5-one derivatives," Journal of Chemistry and Chemical Engeneering, vol. 9, pp. 1-14, 2015. 

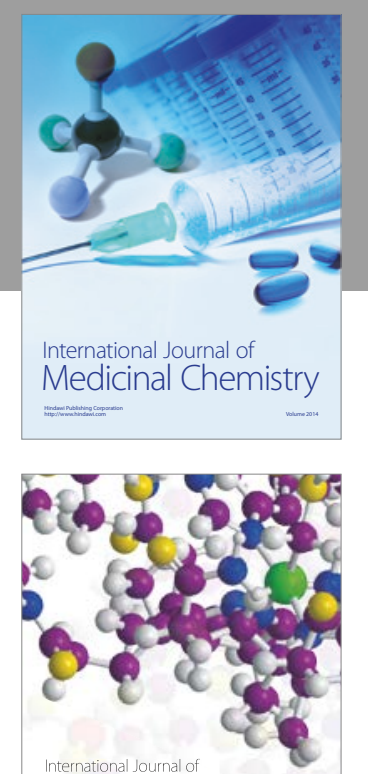

Carbohydrate Chemistry

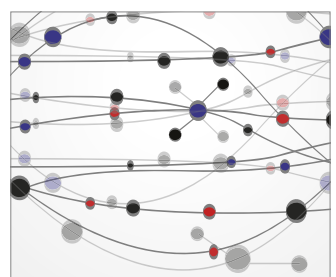

The Scientific World Journal
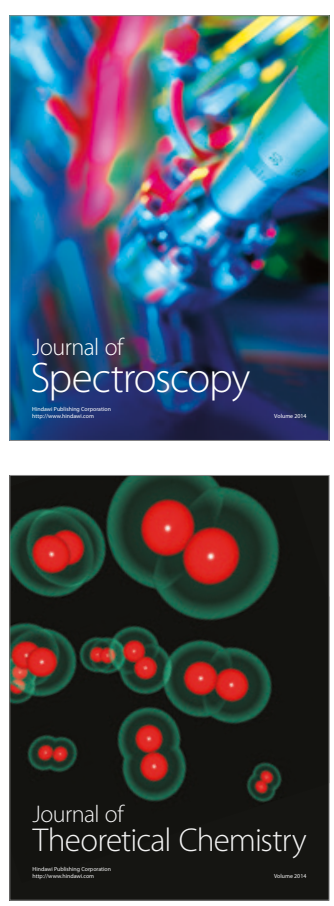
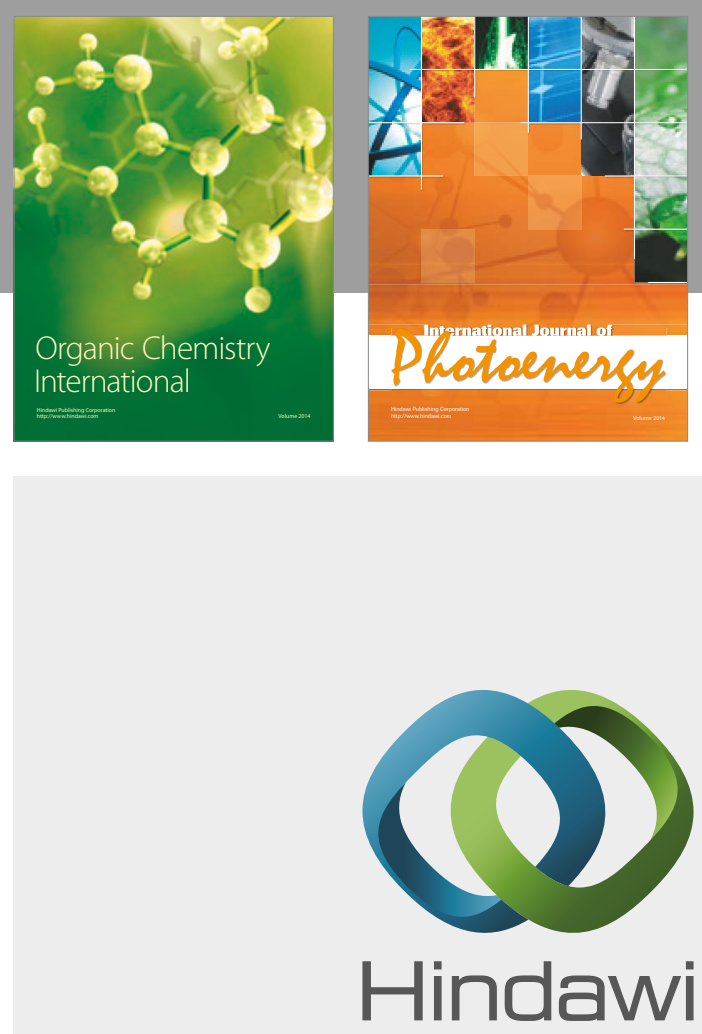

Submit your manuscripts at

https://www.hindawi.com

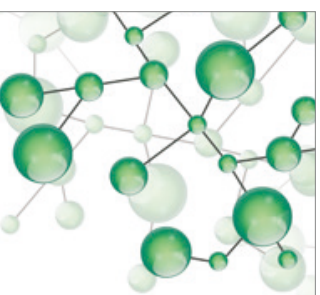

International Journal of

Inorganic Chemistry

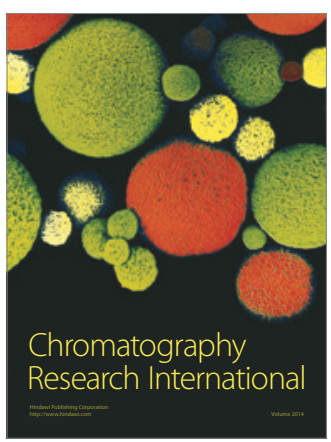

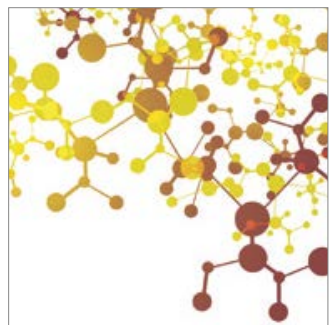

Applied Chemistry
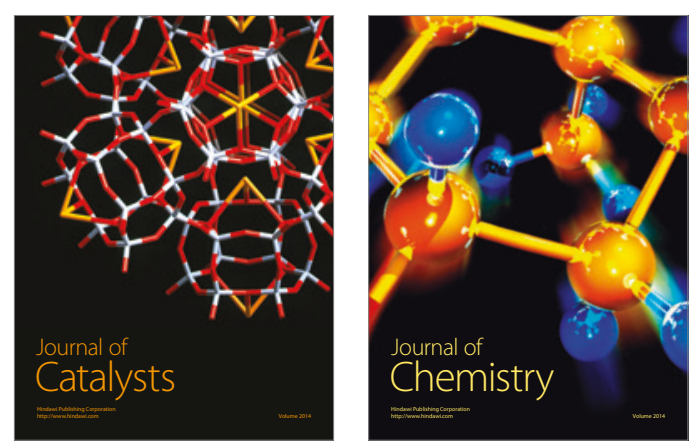
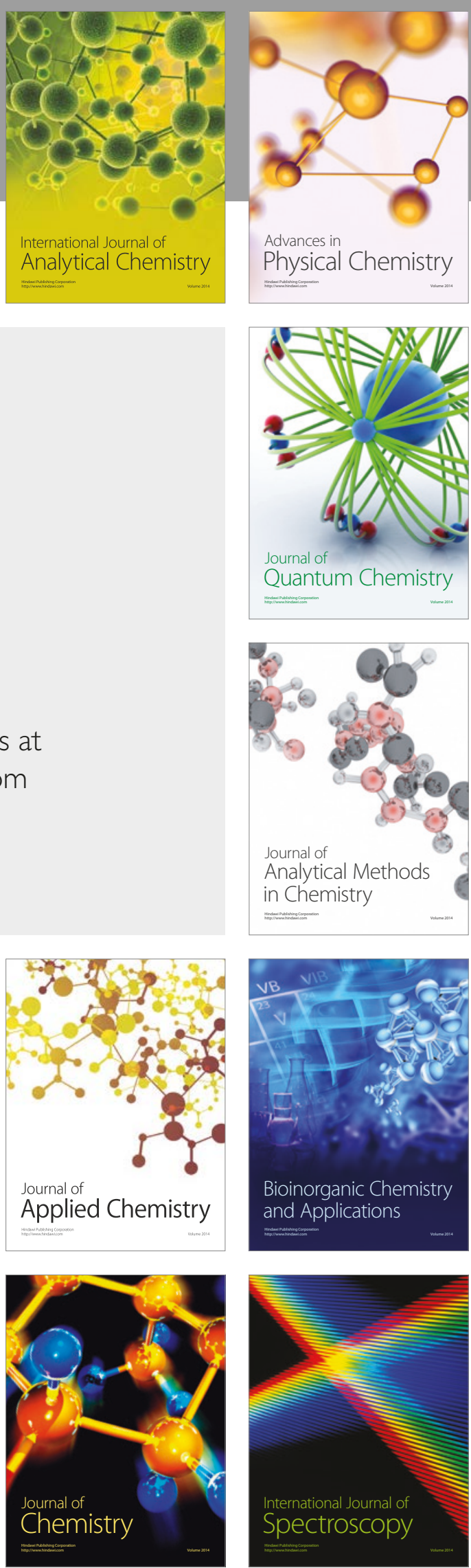